\title{
Symposium Québec-France 2008 santé respiratoire, Centre des congrès de Québec, December 3 to 6, 2008
}

\begin{abstract}
1
EVALUATION SUR BANC DES MESURES DE PROTECTION DE LA VOIE EXPIRATOIRE EN VENTILATION MÉCANIQUE INFLUENCE DU TYPE DE FILTRE UTILISÉ ET DU TYPE DE CIRCUIT D'HUMIDIFICATION

E L'Her, F Lellouche

Centres de Recherche Hôtel-Dieu de Lévis et Université Laval

L'utilisation d'aérosols en ventilation mécanique impose des mesures de protection de la voie expiratoire afin d'éviter des dysfonctionnements. Les objectifs de cette étude sont : 1 - de valider les données fournies par les constructeurs de filtres; 2 - d'évaluer leurs caractéristiques en fonction du mode d'humidification et du type de circuit utilisé. Les mesures ont été réalisées à débit continu (de 10 à $100 \mathrm{~L} / \mathrm{min}$ ) et température constante $\left(21^{\circ} \mathrm{C}\right)$. Le dispositif expérimental utilisé comportait un banc de mesure des débits et pressions (FlowAnalyser PF300TM); l'aérosoliseur utilisé était un modèle piézoélectrique (Aeroneb proTM ; $6 \mathrm{MU}$ Colimycine/24h). Les différents filtres testés comportaient des filtres HME, antibactériens, ainsi qu'un filtre dédié à cette tâche. Trois catégories de performances intrinsèques des filtres ont pu être individualisées: bonne qualité $(\mathrm{n}=2)$; qualité intermédiaire $(\mathrm{n}=8)$; mauvaise qualité - non adéquats $(\mathrm{n}=2)$. En cours d'aérosolisation, le filtre dédié à la tâche a permis une protection efficace du circuit, quel que soit le type de circuit utilisé, à l'exception notable des circuits non chauffés; Les filtres HME par contre, ne doivent en aucun cas être utilisés car des occlusions ont été observées dans des délais courts (de 2 à 7 h). Les filtres antibactériens ont quand à eux permis une protection satisfaisante, mais uniquement en cas d'utilisation de circuits bi-chauffés. En conclusion, la protection du circuit expiratoire est susceptible d'entrainer des occlusions brutales, en fonction du mode d'humidification utilisé. Cette notion doit être prise en compte dans une optique de sécurisation du patient.
\end{abstract}

\section{2}

COMPARAISON DE L'ÉTAT DE SANTÉ DES DEUX COHORTES D'ENFANTS ATTEINTS DE MUCOVISCIDOSE ET SUIVIS DANS LES CENTRES DE GRENOBLE ET QUÉBEC : IMPACT DE LA PRISE EN CHARGE ET DE L'ORGANISATION DES SOINS

E Hullo ${ }^{1}$, P Daigneault ${ }^{2}$, C Llerena ${ }^{1}$, D Plantaz ${ }^{1}$, I Pin ${ }^{1}$

${ }^{1}$ Département de Pédiatrie, CHU Grenoble (France); ${ }^{2}$ Service de Pneumologie Pédiatrique, CHUL Québec (Canada)

L'état de santé des patients atteints de mucoviscidose dépend de l'interaction entre des facteurs génétiques, environnementaux, et des éléments de la prise en charge.

OBJECTIF: Comparer l'état de santé des 2 cohortes d'enfants suivis dans les centres de Grenoble et Québec, afin de rechercher un éventuel impact des pratiques médicales.

METHODES: Etude épidémiologique descriptive et comparative, basée sur le recueil rétrospectif et la comparaison de données épidémiologiques concernant l'état de santé respiratoire et nutritionnel, ainsi que la prise en charge des 203 enfants atteints de mucoviscidose, suivis dans les centres de Grenoble ( $\mathrm{n}=85)$ et Québec ( $\mathrm{n}=118)$ au cours de l'année 2006.

RESULTATS: Lâge moyen des enfants suivis à Grenoble est plus jeune (7.7 vs 10.6 ans). Les paramètres de fonction respiratoire (VEMS et la $\mathrm{CVF}$ ), et l'IMC des patients grenoblois sont inférieurs à ceux des patients québecois $(\mathrm{p}<0.01)$. Les enfants suivis à Grenoble bénéficient d'un suivi plus rapproché $(\mathrm{p}=0.04)$. La RhDnase inhalée et de l'antibiothérapie (IV ou $\mathrm{PO}$ ) sont plus utilisées à Grenoble, où les cures d'antibiothérapie sont plus souvent organisées à domicile. La tobramycine inhalée est plus fréquemment prescrite à Québec, et le nombre moyen hebdomadaire de séances de kinésithérapie respiratoire y est plus élevé (9.3 vs 3.1).

CONCLUSION: Ces résultats préliminaires tendent à montrer que l'état de santé des patients suivis à Grenoble est plus sévère, et confirment l'existence de différences de prise en charge entre les centres de Grenoble et Québec. Des analyses complémentaires sont nécessaires pour mesurer l'impact respectif de ces facteurs sur l'état de santé de ces populations.

\section{3}

SIGNALISATION DE L'APOPTOSE INDUITE PAR CRYOCHIMIOTHERAPIE DANS UN MODELE DE CANCER PULMONAIRE GREFFE A DES SOURIS SCID

V Forest, $\mathbf{R}$ Hadjeres, $\mathbf{R}$ Bertrand, $\mathbf{R}$ Jean-François

Centre de Recherche du Centre Hospitalier de l'Université de Montréal (CHUM) / Institut du Cancer de Montréal, Montréal, Québec

CONTEXTE : La cryochirurgie représente une technique chirurgicale minimalement invasive, utilisée notamment dans le traitement du cancer du poumon, seule ou combinée à d'autres thérapies.

BUT DE L'ETUDE : Définir les paramètres optimaux pour un traitement combiné de cryochirurgie (protoxyde d'azote) et chimiothérapie (vinorelbine ditartrate, VNB) et caractériser les mécanismes moléculaires de l'apoptose induite par ce traitement.

MATERIELS ET METHODES : Dans un modèle d'adénocarcinome pulmonaire humain greffé à des souris SCID, la croissance tumorale a été comparée suite à différentes combinaisons de traitements. L'induction de la mort cellulaire et ses mécanismes ont été étudiés par des marquages immunohistochimiques et par PCR quantitative en temps réel.

RESULTATS : Aucun bénéfice n'est apparu quand cryothérapie et VNB étaient données simultanément. En revanche, les volumes tumoraux étaient significativement réduits après un traitement séquentiel. La séquence de traitement n'avait aucune influence sur l'inhibition de la croissance tumorale. Quand la VNB était administrée 48h avant la cryochirurgie, le nombre de cellules apoptotiques était significativement augmenté $48 \mathrm{~h}$ post-traitement, et était corrélé à une expression accrue des protéines pro-apoptotiques Puma, Noxa et Bim-EL. Aucun changement significatif n'a été observé au niveau de l'expression des protéines antiapoptotiques Bcl-xL et Bcl-2.

CONCLUSION : Ces résultats suggèrent que l'administration de VNB $48 \mathrm{~h}$ avant cryochirurgie induit plus efficacement l'apoptose que les autres protocoles testés.

\section{4}

DIAGNOSTIC D'HTA AU COURS DU SYNDROME D'APNÉES OBSTRUCTIVES DU SOMMEIL : MAPA OU AUTOMESURE?

I Boutin ${ }^{1}$, JL Pépin², R Tamisier², G Barone-Rochette², P Lévy², JP Baguet $^{2}$

${ }^{1}$ Hôpital Laval, Québec, Canada; ${ }^{2} \mathrm{CHU}$ Grenoble, Grenoble, France OBJECTIF : La prévalence de l'HTA est élevée au cours du syndrome d'apnées obstructives du sommeil (SAOS). L'intérêt de l'automesure de la PA à domicile (AM) n'a jamais été étudié au cours du SAOS. L'objectif de notre étude est de déterminer l'apport de l'AM pour le diagnostic d'HTA au cours du SAOS, en comparaison aux données de la mesure clinique et de la MAPA. 
MÉTHODES ET RÉSULTATS : 71 patients SAOS consécutifs (55 hommes, âge : $50 \pm 10$ ans, IMC : $26 \pm 3 \mathrm{~kg} / \mathrm{m}^{2}$, PA clinique : $129 \pm 14 / 85 \pm 9$ $\mathrm{mmHg}$, index d'apnées-hypopnées : $42 \pm 16 / \mathrm{h}$ ), non connus comme être porteurs d'une maladie cardiovasculaire, ont bénéficié d'une mesure de la PA en clinique, par MAPA et en AM. En MAPA, 51 patients (72\%) étaient hypertendus contre 17 (24\%) en utilisant l'AM et $22(31 \%)$ en clinique. 32 patients $(45 \%)$ avaient une HTA diurne en MAPA et 46 (65\%) étaient hypertendus la nuit. 19 (27\%) patients n'avaient pour seule anomalie qu'une HTA nocturne. Une HTA blouse blanche était retrouvée par la MAPA chez un 1 patient (1\%) et par l'AM chez 9 (13\%) patients. En comparaison à la MAPA, la sensibilité de l'AM pour le diagnostic d'HTA est de $31 \%$, sa spécificité de $95 \%$ et sa valeur prédictive négative de $35 \%$.

CONCLUSIONS : Du fait que l'HTA des patients porteurs d'un SAOS soit à prédominance nocturne, l'AM n'a que peu d'intérêt dans cette pathologie certes spécifique mais loin d'être rare. La MAPA est donc la méthode de référence pour le diagnostic d'HTA en présence d'un SAOS.

\section{5}

RÔLE DE $\alpha 5 \beta 1$ DANS L'INTERACTION ENTRE LES LYMPHOCYTES T ET LES FIBROBLASTES BRONCHIQUES DANS L'ASTHME

L Loubaki, V Turmel, S Plante, W Mourad, J Chakir

Centre Recherche, Hôpital Laval, Institut Universitaire de Cardiologie et de Pneumologie de I’Université Laval, Québec, Canada

L'asthme est une maladie inflammatoire chronique des voies aériennes caractérisée par l'infiltration de cellules inflammatoires activées comme les lymphocytes $\mathrm{T}$ dans la muqueuse bronchique. Ces lymphocytes $\mathrm{T}$ sont en contact étroit avec les cellules résidentes augmentant ainsi la possibilité d'interaction avec les cellules structurales telles les fibroblastes.

OBJECTIF : Évaluer l'effet de l'interaction entre les cellules $\mathrm{T}$ et les fibroblastes bronchiques sur la production d'interleukine-6 (IL-6).

MÉTHODES : Les fibroblastes bronchiques ont été isolés à partir de biopsies bronchiques provenant de patients sains non atopiques et asthmatiques légers. Les cellules $\mathrm{T}$ ont été purifiées du sang périphérique des mêmes patients. Les co-cultures de fibroblastes sains (FS) ou asthmatique (FA) à confluence avec des cellules T ont été réalisées en présence ou en absence d'anticorps bloquant anti-intégrine $\alpha 5$. L'ARN total a été purifié et l'expression de l'IL-6 a été évaluer par PCR en temps réel.

RÉSULTATS : Le contact direct des lymphocytes T stimule la production d'IL-6 par les fibroblastes tant normaux qu'asthmatiques. Cet effet était plus marqué chez les FA que chez les FS $(284,89 \pm 48,1 \%$ vs $537,33 \pm 94,5 \%$; $\mathrm{p}=0,05)$. La co-culture en présence d'anti- $\alpha 5$ ramène l'expression d'IL-6 à son niveau basal chez les FA $(537,33 \pm 94,5 \%$ vs $117,6 \pm 17,3 \%$; $=0.001)$ mais, pas chez les FS $(284,89 \pm 48,1 \%$ vs $289.9 \pm 65,6 \% ; p=0,6)$.

CONCLUSION : Ces résultats suggèrent que les interactions cellulaires particulièrement celle entre les fibroblastes et les lymphocytes $T$ jouent un rôle important dans la modulation de la réponse inflammatoire dans l'asthme.

\section{6}

THE PHARMACOKINETICS OF TPI 1020, A NOVEL ANTIINFLAMMATORY COMPOUND IN DEVELOPMENT FOR COPD AND OTHER RESPIRATORY DISORDERS

A Brasey, M Fortin, P Aubé, K Moktéfi, R Séguin, A Guimond, N Ferrari

Topigen Pharmaceuticals Inc.

BACKGROUND: TPI 1020 is a novel anti-inflammatory compound with a dual mechanism of action involving corticosteroid activity (derived from its metabolite budesonide) and release of nitric oxide, currently in clinical development for the treatment of COPD.

OBJECTIVE: To assess the pharmacokinetics of TPI 1020 and its metabolites following a single dose delivered via pulmonary and oral administration.

METHODS: TPI 1020 metabolism (10 $\mu \mathrm{M}$ for up to $6 \mathrm{~h})$ was assessed in vitro in human plasma, lung and liver S9 fractions. In vivo metabolism was assessed in mice following both intratracheal and oral single dose $(8 \mathrm{mg} / \mathrm{kg})$ administration by measuring plasma levels of TPI 1020 and its metabolites.

RESULTS: In vitro, after incubation in plasma and lung S9 fraction approximately $80 \%$ of TPI 1020 had not been metabolised while only $20 \%$ remained in liver. The three main metabolites were: budesonide, des-nitro TPI 1020 (denoted NCX 996) and the NO-donating moiety (denoted NCX 1048). In mice, plasma levels of TPI 1020 and its metabolites were 2.5 to 7 -fold higher following pulmonary delivery ( $\mathrm{T}_{\max }$ of $30 \mathrm{~min}$ ) compared to the oral route ( $\mathrm{T}_{\max }$ of $\left.60 \mathrm{~min}\right)$. A comparison with budesonide administration showed that, irrespective of administration route, plasma levels of TPI 1020-derived budesonide were markedly lower compared to levels observed following equivalent dose of budesonide.

CONCLUSIONS: TPI 1020 can be effectively metabolized in the lung and liver. The significant differences in the plasma levels of TPI 1020-derived budesonide as compared to levels of budesonide alone is consistent with lower systemic corticosteroid exposure associated with TPI 1020 pulmonary administration.

\section{7}

IMPACT DE LA RÉPONSE INFLAMMATOIRE SUR LA RÉPARATION DE L'ÉPITHÉLIUM BRONCHIQUE FIBROSE KYSTIQUE

NTN Trinh ${ }^{1,2}$, A Privé ${ }^{2}$, É Maillé1, E Brochiero1, ${ }^{1,2}$

${ }^{1}$ Département de Médecine, Université de Montréal; et ${ }^{2}$ Centre de Recherche du CHUM (CR- CHUM) Hôtel-Dieu

Chez les patients Fibrose Kystique (FK), les infections bactériennes et l'inflammation causent une destruction progressive de l'épithélium pulmonaire, pouvant entraîner une détresse respiratoire. Plusieurs traitements tentent de contrôler ces infections/inflammations, mais on ignore l'impact de ces paramètres sur la régénération des tissus lésés. Grâce à un modèle de lésion de l'épithélium bronchique sain $(\mathrm{NuLi})$ et $\mathrm{FK}(\mathrm{CuFi})$, nous avons récemment montré que la réparation des $\mathrm{CuFi}$ était retardée par rapport à celle des NuLi. Ce retard est accompagné d'une altération de la réponse à l'EGF et de la fonction des canaux $K+, 2$ éléments cruciaux à la réparation épithéliale. Nous avons donc décidé d'étudier l'impact de l'infection (LPS de Pseudomonas aeruginosa) et de l'inflammation (cytokines proinflammatoires : IL1-b, IL-6, IFN-g, TNF) sur les mécanismes de réparation, la réponse à l'EGF et les canaux $\mathrm{K}+$. Le LPS à $10 \mathrm{ug} / \mathrm{ml}$ stimule la réparation des $\mathrm{NuLi}$ et $\mathrm{CuFi}$ alors que de plus fortes doses ( 25 et $100 \mathrm{ug} / \mathrm{ml}$ ) inhibent la réparation et migration cellulaire. L'IFN-g, le TNF et une combinaison des 4 cytokines stimule la réparation des $\mathrm{NuLi}$ (50\%) et CuFi (200\%), diminuant ainsi le retard de réparation des CuFi. L'effet du TNF est aboli en présence des inhibiteurs des récepteurs EGF (AG1478+AG825), suggérant un lien entre EGFR et la réponse au TNF. Enfin, le TNF;stimule l'expression du canal K+ KvLQT1. En conclusion, il semble exister une relation entre l'inflammation, la voie EGF/EGFR et les canaux $\mathrm{K}+$. Cette étude permettra de mieux comprendre le rôle de l'inflammation dans la réparation de l'épithélium pulmonaire et de développer des thérapies antiinflammatoires mieux adaptées.

\section{8}

INFLUENCE DE LA FUMÉE SECONDAIRE SUR LES RÉFLEXES LARYNGÉS DÉCLENCHÉS PAR UNE SOLUTION ACIDE CHEZ L'AGNEAU NOUVEAU-NÉ

M St-Hilaire, C Duvareilles, A-M Carreau, O Avoine, P Micheau, J-P Praud

Unité de Recherche Respiratoire Néonatale, Université de

Sherbrooke

Dans un organisme mature, les reflux laryngo-pharyngés de liquide gastrique acide déclenchent des réflexes de protection afin d'éviter l'aspiration trachéale. Malheuresuement, chez certains nouveau-nés, des apnées-bradycardies réflexes sont parfois déclenchées par ces reflux en période néonatale et sont probablement impliqués dans des cas de mort subite du nourrisson. Certaines conditions favoriseraient la survenue de ces apnéesbradycardies réflexes. Le but de ce projet est de tester l'hypothèse que l'exposition à la fumée de cigarette est une de ces conditions. Six agneaux 
ont été exposés à la fumée de cigarette (20 cig/jour) du 1er au 17 ème jour de vie (J17) et comparés à 6 agneaux contrôles. Une instrumentation chirurgicale chronique a été effectuée à J14. À J17, un reflux laryngé de liquide acide a été mimé par injection d' $\mathrm{HCl}(\mathrm{pH} 2,0.5 \mathrm{ml})$ durant le sommeil. Les résultats préliminaires montrent que la fumée engendre une diminution plus importante de la fréquence respiratoire [contrôle $=49,4$ $(\mathrm{SD} 15)$ fumée $=67,2(\mathrm{SD} 9)$ ] et de la fréquence cardiaque [contrôle = 23,6 (SD 4) fumée = 31,8 (SD 9)] suite à une stimulation laryngée acide. En conclusion, l'exposition à la fumée de cigarette augmente l'inhibition cardiorespiratoire déclenchée par le contact d'un liquide acide avec le larynx. L'implication de cette inhibition dans la survenue d'apnées-bradycardies dangereuses chez certains jeunes nourrissons reste à démontrer. Supporté par les IRSC.

\section{9} INHIBITION DES PROCESSUS DE MIGRATION ET DE
PROLIFÉRATION DES CELLULES PULMONAIRES
CANCÉREUSES PAR DES INHIBITEURS DES CANAUX K+ CANCÉREUSES PAR DES INHIBITEURS DES CANAUX K+
${\text { A } \text { Privé }^{2} \text {, OD Charron² }}^{2}$ L Menger ${ }^{2}$, E Maillé ${ }^{2}$, E Brochiero ${ }^{1,2}$ ${ }^{1}$ Département de Médecine, Université de Montréal; et ${ }^{2}$ Centre de recherche du CHUM (CRCHUM) Hôtel-Dieu

En dépit des avancées en chimiothérapie, le cancer du poumon demeure la principale cause de décès chez les patients atteints de cancer, avec une survie relative à 5 ans de $15 \%$. Une meilleure connaissance des mécanismes impliqués dans le développement et la propagation du cancer pulmonaire est donc nécessaire pour concevoir de nouvelles thérapies. Nous avons ainsi récemment posé l'hypothèse que l'activité des canaux $\mathrm{K}+$, qui module la migration et la prolifération de plusieurs types cellulaires, pourrait être impliquée dans ces processus au sein des cellules pulmonaires tumorales. Pour cela, nous avons effectué des tests de «scratch» (plaies mécaniques) afin d'évaluer la migration et la prolifération des cellules A549 (adénocarcinome broncho-alvéolaire) et H460 (carcinome à large cellules) en présence d'inhibiteurs des canaux KvLQT1, KATP et KCa3.1, fortement exprimés dans ces cellules. La migration cellulaire a également été mesurée en chambre de type Boyden. Nous montrons que le clofilium, le glibenclamide et le TRAM34 (respectivement inhibiteurs des canaux KvLQT1, KATP et KCa3.1) réduisent de façon significative (inhibition de 15 à 60\%) la migration/prolifération des cellules A549 et H460, mesurées dans des conditions de base ou après stimulation à l'EGF. En combinaison, ces agents ont un effet additif, entraînant une inhibition allant jusqu'à $70 \%$. Nos résultats démontrent donc que des inhibiteurs des canaux K+ réduisent efficacement les processus de migration/prolifération des cellules pulmonaires tumorales et pourraient constituer une stratégie prometteuse pour la thérapie du cancer pulmonaire.

\section{0}

\section{FUNCTIONAL INTERACTIONS OF CD154 WITH DIFFERENT RECEPTORS AND THEIR ROLE IN ALLERGEN- INDUCED BRONCHIAL HYPER-RESPONSIVENESS}

GS Hassan, H Alturaihi, DAM Diallo, B Mazer, WM Mourad Lab. Cellular and Molecular Immunology, CHUM, Montreal, QC; Division of Allergy and Immunology, MUHC, Montreal, QC

CD154, a member of the TNF family initially thought to be solely linked to humoral responses, was recently shown to be implicated in inflammatory events such as asthma. In asthma, activated T cells expressed CD154, and resident cells such as fibroblasts and epithelial cells expressed CD40, and alpha 5 beta 1 ( $\alpha 5 \beta 1$ ), the newly identified CD154 receptor, and respond to CD154 by production of cytokines and chemokines. The $\operatorname{IgE}$ production induced by repeated exposure to Aspergillus fumigatus (Af) was markedly suppressed in CD154-/- and CD40/- mice, whereas, the development of bronchial hyper-responsiveness (BHR) was prevented only by the lack of CD154, suggesting that CD154/CD40 interaction is critical for the induction of IgE responses, and that another CD154 receptor may be important for BHR. Based on these data, we hypothesize that CD154 binding to $\alpha 531$ alone or in combination with CD40 may play an important role in the development of human inflammatory diseases such as BHR. Our aims include: 1 ) to further characterize the interaction of CD154 with $\alpha 5 \beta 1$, and 2) to study its function in vitro and in vivo systems. First, the role of CD154 binding to different receptors has been tested. A bidirectional signalling was initiated upon binding of CD154 to CD40 or $\alpha 5 \beta 1$. Next, using structural analysis, our results indicated that distinct CD154 residues are involved in its interaction with $\alpha 5 \beta 1$ and with CD40. Our next goal is to study the role of CD154 binding to CD40 and $\alpha 5 \beta 1$ receptors in animal models. Indeed, we induced BHR in C57BL/6 mice in the presence or absence CD154 interfering agents. Our results showed that BHRinduced by OVA in Balb/c mice was significantly affected by treatment with anti-CD154 mAb, supporting the role of CD154 in BHR. Further experiments will be undertaken to delineate the role of CD40 and/or $\alpha 5 \beta 1$ in this response. These studies will provide considerable insights into the novel CD154 receptor, and highlight new approaches for the treatment of CD154-associated human diseases.

\section{1}

\section{DRUG RESISTANCE AND TB DRUG POLICY: AN ECOLOGIC ANALYSIS}

A Paydar ${ }^{1}$, A Mak ${ }^{1}$, M del Granado 2 , R Zaleskis, H Al-Jahdali ${ }^{4}$, D Menzies ${ }^{1}$

${ }^{1}$ Montreal Chest Institute, McGill University; ${ }^{2}$ Pan American Health Organization; ${ }^{3}$ European Regional Office, WHO; ${ }^{4}$ King Saud Bin Abdulaziz University

BACKGROUND: Tuberculosis (TB) remains a major threat to global health and although curable, it is far from eradication. This reflects poverty, poor health services, political instability, the global HIV pandemic, and increasing occurrence of drug resistance, particularly multi-drug resistance. We have conducted an ecologic study to correlate the national prevalence of drug resistance with national policies regarding the distribution of TB drugs.

METHODS: A questionnaire was completed by participating countries' National TB programme (NTP) directors, about TB treatment regimens, rifampin (RIF) use, and control of TB drugs. The prevalence of drug resistance in all countries was obtained from data published by the World Health Organization. An ecologic analysis was performed. Countries were stratified by prevalence of multi-drug resistance (MDR-TB - resistance to at least isoniazid and RIF): low $(<1 \%)$; intermediate $(1-3 \%)$; and high $(>3 \%)$.

RESULTS: In preliminary analysis - among 58 countries with mean incidence of smear positive pulmonary TB of 56/100,000, and mean MDR prevalence of $3.6 \%, 15$ countries had high MDR prevalence, of whom 9 $(60 \%)$ allowed the sale of TB drugs in the private sector. Uncontrolled access to TB drugs was reported by only 7 of $25(28 \%)$ of countries with intermediate MDR, and 6 of 16 (38\%) countries with low MDR. Countries with high MDR prevalence reported uncontrolled use of Rifampin for an average of 25 years, compared to 19 and 20 years respectively, in the medium and low MDR countries.

CONCLUSIONS: Countries with the highest prevalence of MDR-TB were less likely to have policies that restricted rifampin use to the NTP.

\section{2}

\section{FACTORS INFLUENCING THE USE AND NONUSE OF CONTINUOUS POSITIVE AIRWAY PRESSURE THERAPY: A COMPARATIVE CASE STUDY}

Tracy Meredith Ayow RN MSc $(A)^{1}$, France Paquet RN MSc $(\mathbf{N})^{2}$, Julie Dallaire $\mathrm{RN} \operatorname{MSc}(\mathbf{N})^{2}$, Margaret Purden $\mathbf{N ~ P h D}^{1}$, Katéri Agnes Champagne MD MSc ABSM ${ }^{2,3}$

${ }^{1}$ McGill University School of Nursing, Montreal, Quebec; ${ }^{2}$ McGill University Health Centre, Sleep Disorders Clinic Montreal, Quebec; ${ }^{3}$ McGill University Health Centre, Respiratory Epidemiology \& Clinical Research Unit, Montreal, Quebec The rates of sustained use of Continuous Positive Airway Pressure (CPAP) treatment among adults with obstructive sleep apnea (OSA) appear consistently suboptimal, despite the efficacy of this treatment. Using semistructured interviews, this study identified facilitators and barriers toward CPAP use, following treatment initiation, among patients with obstructive sleep apnea. A purposive sample of eight patients, representing extreme 
differences in CPAP use, was recruited from a multi-site Sleep Disorders Clinic at a tertiary health centre. Perceived physical, psychological, and social factors were found to influence both CPAP use and nonuse. It was revealed that the way that patients feel about themselves is of utmost importance in how they manage their OSA with or without CPAP. This study underlines the necessity of working with patients and their families in creating social environments that are both accepting and supportive to the OSA patient.

\section{3}

\section{TB TREATMENT OUTCOMES WITH STANDARDIZED REGIMENS THAT ARE RECOMMENDED BY WHO}

I Martin ${ }^{1}$, A Paydar ${ }^{1}$, A Benedetti ${ }^{1}$, M Pai ${ }^{1}$, S Royce ${ }^{2}$, M Grzemska ${ }^{2}$, D Menzies ${ }^{1}$

${ }^{1}$ Montreal Chest Institute, McGill University; ${ }^{2}$ WHO

BACKGROUND: Tuberculosis (TB) remains a major global health problem, with more than 9 million new cases annually and 2 million deaths. The World Health organization has recommended use of standardized treatment regimens as part of the DOTS strategy. We have conducted a systematic review and meta-analysis of all published randomized trials to examine the risk of failure, relapse and acquired drug resistance (ADR) with use of standardized regimens to treat new cases.

METHODS: The published literature was identified through search of PubMed, Embase, and Cochrane databases. Titles identified were screened by two reviewers, who then screened abstracts from selected titles, then full text were reviewed of selected abstracts. Studies were assessed with regard to design, methods, quality, and treatment outcomes. Pooled estimates, stratified by major covariates, were analyzed using a random effects model in SAS.

RESULTS: The standard 6-month rifampin regimen (2HRZE/4HR) had overall failure rate of $0.6 \%$, relapse rate of $4 \%$, and ADR rate of $0.4 \%$, compared to rates of $1.4 \%, 10.1 \%$, and $1.1 \%$ respectively with the 2 -month Rifampin regimen (2HRZE/6HE). Overall rates of these 3 outcomes were 10-20 times higher in the presence of INH resistance, and even worse if there was resistance to INH plus one other drug (but not including RIF). CONCLUSIONS: Treatment outcomes with the standard 2-month rifampin were significantly and substantially worse than with the standard 6-month Rifampin regimen. Outcomes were much worse in the presence of initial drug resistance with either regimen.

\section{4}

\section{EXPRESSION OF PRO-ALLERGIC INTERLEUKIN-33 BY AIRWAY EPITHELIAL CELLS IN HUMAN ASTHMA}

D Préfontaine, J Nadigel, N Takeda, S Lajoie-Kadoch, S Foley, R Olivenstein, P Ernst, C Lemière. JG Martin, Q Hamid Meakins-Christie Laboratories \& Montreal Chest Hospital Research Institute, McGill University; Sacré-Coeur Hospital, University of Montreal

RATIONALE: Airway Epithelial cells (AECs) significantly contribute to the inflammatory profile seen in respiratory disease like asthma as they produce a wide array of mediators. Although previous investigation revealed an increased IL-33 gene expression asthma, protein expression in the lung and especially in AECs have not been studied.

METHODS: Immunocytochemistry (ICC) was used to assess IL-33 expression in endobronchial biopsy tissues from asthmatic patients as compared to healthy controls. Regulation of IL-33 expression was also studied in normal human bronchial epithelial cells (NHBE) cultured under various inflammatory conditions. Reverse transcriptase- and real-time quantitative polymerase chain reaction, immunoblotting and ELISA were used to assess gene transcription, protein expression and secretion, respectively.

RESULTS: Our ICCs proposed AECs as a significant source of IL-33 protein. Immunoreactivity was markedly increased in patients with asthma compared to controls. NHBE cells express IL-33 constitutively. Proinflammatory cytokines TNF-alpha and IFN-gamma were potent inducers of IL-33 expression. IL-33 appears to be poorly released and to remain inside the cells, although evidence for nuclear and transcriptional roles is still lacking.
CONCLUSIONS: This study demonstrates an increased IL-33 protein expression in lung tissue from patients with asthma. AECs appear as a major source of IL-33. IL-33 expression was confirmed in vitro in NHBE and was increased by pro-inflammatory cytokines. These data support the hypothesis that IL-33 modulates the inflammatory milieu in bronchial asthma, especially through its role in epithelial cells.

\section{5}

\section{RELATIONSHIP BETWEEN MUSCLE WEAKNESS AND FUNCTIONAL CAPACITY IN IDIOPATHIC PULMONARY ARTERIAL HYPERTENSION (IPAH)}

V Mainguy, D Saey, F Maltais, S Martel, M Simon, S Provencher Centre de recherche de I'Hôpital Laval, Québec, Canada

BACKGROUND: Most IPAH patients display persistent exercise intolerance despite current therapies. Clinical observations suggest that this limitation is partly related to intrinsic peripheral muscle abnormalities. We tested the hypothesis that IPAH patients present peripheral muscular abnormalities that correlates with their exercise intolerance.

METHODS: The quadriceps (Qps) muscle characteristics of 10 consecutive IPAH patients (WHO FC II/III:7/3) were compared to 10 sedentary controls. Subjects were matched for age, gender and BMI. Peak VO2, sixminute walked distance (6MWD), Qps strength by maximal voluntary contraction (MVC) and non-volitional magnetic stimulation of the femoral nerve (TWq), limb muscle cross sectional area (CSA) by CT scan and Qps biopsy for muscle fiber typing, enzymes concentration and capillarity were performed.

RESULTS: IPAH patients displayed lower exercise capacity as assessed by 6MWD (424(65) vs 653(66) meters, $\mathrm{p}<0.001)$ and peak VO2 (18.2(5.0) vs 31.6(6.6) ml.kg-1.min-1, p<0.001) and lower MVC (36(10) vs 44(7) $\mathrm{Kg}, \mathrm{p}=0.05)$, TWq $(6.8(2.1)$ vs $9.4(2.2) \mathrm{Kg}, \mathrm{p}=0.01)$ and Type I muscle fiber type $(38(13)$ vs $50(8) \%, p=0.03)$ as compared to controls. CSA tended to be lower, whereas muscle fiber IIb and PFK glycolytic enzyme tended to be higher in IPAH. No capillarity differences were found between the two groups. In IPAH, peak VO2 correlated to TWq $(r=0.65$, $\mathrm{p}<0.05)$.

CONCLUSIONS: IPAH patients exhibit lower exercise tolerance, Qps strength and Type I muscle fiber than sedentary controls. The correlation between non-volitional strength and peak VO2 suggests peripheral muscle abnormalities may be implicated in patients' exercise intolerance.

\section{6}

\section{BRONCHECTASIES ET MYCOBACTÉRIES ATYPIQUES : UNE REVUE DE 12 OBSERVATIONS CONSÉCUTIVES}

B Melloni, A Croitoru, A Bakayoko, M Dupuy-Grasset, C Martin, F Bonnaud

Service de Pathologie Respiratoire, Service de BactériologieVirologie, CHU Limoges, France

Les infections respiratoires à mycobactéries atypiques peuvent s'observer chez des patients immunocompétents présentant ou non des lésions préexistantes. Dix femmes et deux hommes, tous immunocompétents, ont été hospitalisés pour la persistance d'une infection pulmonaire. L'analyse des antécédents retrouvait dans 6 cas la notion de bronchectasies anciennes. Les cultures bactériologiques ont mis en évidence la présence du complexe M Avium-Intracellulare ou MAC ( $n=9)$, M scrofulaceum $(n=1)$ et une association de MAC et M Kansasii $(n=1)$. Pour MAC, une résistance primaire était démontrée dans 5 cas pour les macrolides, 3 cas pour la rifampicine, et un cas respectivement pour l'INH, la pyrazinamide et la streptomycine. La présentation en imagerie était dans les cas des bronchectasies. En absence de lésion préexistante connue, on retrouvait des infiltrats associés ou non des nodules, voire des cavernes. Les patients ont tous été traité par une triple antibiothérapie et seuls 4 patients ont bénéficié d'un geste chirurgical. L'évolution a été favorable sur le plan clinique et bactériologique que dans 3 cas seulement. Pour les autres situations, l'évolution est marquée par la persistance d'une infection chronique malgré la thérapeutique avec cachexie et apparition d'une insuffisance respiratoire chronique (2 décès).

En conclusion, deux présentations distinctes sont observées avec ou non des lésions pulmonaires préexistantes. En absence de lésion préexistante, la 
présentation révélatrice touche la femme de plus de 50 ans avec un aspect d'atteinte interstitielle (Syndrome de Lady Wintermer). L'efficacité des antibiotiques reste modeste le plus souvent.

\section{7}

\section{EFFETS DU NEURO-ASSERVISSEMENT DE LA VENTILATION ASSISTÉE (NAVA) SUR LA VARIABILITÉ ET LE CHAOS VENTILATOIRE CHEZ INSUFFISANCE RESPIRATOIRE AIGUE}

M Schmidt, A Demoule, T Mirkovic, A Duguet, N Bautin, C Straus, T Similowski, S Gottfried

Laboratoire de Physiopathologie Respiratoire, Groupe Hospitalier Pitié-Salpêtrière, UPRES EA 2397, Université Paris VI Pierre et Marie Curie, Paris, France; Meakins-Christie Laboratories, Dept. of Medicine, McGill University, Montreal, Quebec, Canada

INTRODUCTION: Le rythme ventilatoire, comme le rythme cardiaque, n'est pas monotone mais variable au cours du temps. La nature chaotique de la commande ventilatoire sous-tend une variabilité des cycles les uns par rapport aux autres. La variabilité ventilatoire diminue au cours de certaines situations pathologiques et de façon générale lorsque la charge imposée augmenteé. Le neuro-asservissement de la ventilation assistée (NAVA) ajuste l'assistance délivrée par le ventilateur à l'activité électromyographique du diaphragme (Edi). Cette étude teste l'hypothèse que la variabilité ventilatoire augmente lors de l'application du NAVA chez des patients préalablement en aide inspiratoire (AI).

METHODES: Chez 10 patients intubés, la variabilité ventilatoire a été caractérisée en AI puis en mode NAVA à 4 niveaux croissants d'assistance (NAVA 1-4 cm $\mathrm{cm}_{2} \mathrm{O} / \mu \mathrm{V}$ Edi), de la façon suivante: 1 ) calcul du coefficient de variation $(\mathrm{CoV})$ des descripteurs du cycle ventilatoire; 2 ) détection du chaos ventilatoire (titration de bruit, $\mathrm{TdB}$ ) et quantification de la sensibilité aux conditions initiales (le plus grand exposant de Lyapunov, LLE). RESULTATS: Le passage de AI à NAVA ne modifie pas la ventilationminute ni les valeurs moyennes des différents descripteurs du cycle ventilatoire. Le $\mathrm{CoV}$ de ces descripteurs est supérieur en mode NAVA par rapport à l'AI, et augmente significativement à mesure que le niveau d'assistance croît $(p<0.05)$. La TdB atteste de la présence de chaos, avec une augmentation significative de LLE à mesure que le niveau d'assistance augmente.

CONCLUSIONS: Le NAVA est associé à une variabilité ventilatoire et le chaos plus élevée que AI, à niveau constant de ventilation.

\section{8}

\section{RESPIR.COM : PROGRAMME DE SOINS INTÉGRÉS POUR LA CLIENTÈLE MPOC}

M Labrecque MD MSC, C Riopel BSC, B Tardivel BSC, H Favreau PHDc, K Lavoie PHD, M Julien MD

Centre de recherche de l'Hôpital Sacré-Coeur de Montréal

Respir.com est un projet de soins intégrés pour la clientèle MPOC de l'Hôpital Sacré-Cœur de Montréal (HSC) impliquant 4 CLSC affiliés (Centre Locaux de Services) les cliniques médicales privées, et l'HSC.

OBJECTIFS GÉNÉRAUX : 1.Utilisation appropriée des ressources. 2.Modèle de soins basé sur l'éducation et la Prévention.3. Assurer une continuité dans les soins.4. Réduction de la duplication et de la fragmentation des soins.

OBJECTIFS SPÉCIFIQUES : 1. Durant l'hospitalisation évaluer les besoins spécifiques à la MPOC et effectuer une référence aux services appropriés. 2. Au moment du congé, assurer le lien avec la première ligne; médecin de famille, CLSC et pharmacien en ce qui concerne le sommaire médical, la médication de départ et le plan de soins prévu. 3. Prévenir les complications reliées à la MPOC.A cet égard l'intervenante Pivot joue un rôle primordial dans l'organisation des soins au niveau primaire (lien avec les CLSC, et Médecins de première ligne). Après un recueil des données sociodémographiques, médicales et des habitudes de vie, elle évaluera le degré de motivation du patient à participer aux programmes spécifiques à la MPOC et évaluera par un bref enseignement le niveau de connaissance du patient face à l'autogestion de la maladie. Après entente avec le reste de l'équipe traitante elle le référera selon les besoins identifiés à un ou plusieurs des programmes disponibles suivant. Programmes spécifiques à la clientèle MPOC : PACT programme d'aide à la cessation tabagique. CEAM centre d'enseignement aux asthmatiques et MPOC. Réadaptation pulmonaire. RESPIR réseau externe de soins aux patients insuffisants respiratoires. SRSAD Services respiratoires de Soins à domicile. CLSC centre local de services

\section{9}

\section{SOINS INTÉGRÉS POUR LA CLIENTÈLE MPOC; EFFICACITÉ SUPÉRIEURE CHEZ LA FEMME}

M Labrecque MD MSc, G Moullec PHD, K Raby MSC, M Julien,

K Lavoie PHD

Centre de recherche Hôpital Sacré-Cœur de Montréal

L'objectif de ce devis de recherche évaluative est de mesurer l'efficacité d'un modèle de soins intégrés pour la clientèle MPOC sur l'utilisation des services de santé en tenant compte des indicateurs suivants

- Le nombre de visite à l'urgence;

- Le nombre d'hospitalisation;

Il s'agit d'un devis prospectif du type pré - post avec un groupe contrôle parallèle sur une période de 12 mois. Le programme de Soins Intégrés Respir.com a fait l'objet d'une description dans un abrégé connexe.

MÉTHODE : La population ciblée est la population âgée de plus de 40 ans, diagnostiquée MPOC selon les critères de GOLD. L'échantillon à l'étude est constitué des sujets qui consultent à l'urgence, ou qui sont hospitalisés pour MPOC à l'Hôpital du Sacré-Cœur de Montréal entre le premier janvier 2005 et le premier janvier 2006 et dont les besoins spécifiques à la MPOC sont évalués par notre intervenante pivot qui réfèrent les patients aux différentes composantes du programme de soins intégrés. Le groupe contrôle est constitué des sujets du même groupe d'âge diagnostiqué MPOC qui consultent à l'urgence, ou qui sont hospitalisés pour MPOC pendant la même période dans un hôpital de soins primaires sur la Rive Nord de Montréal ou les services spécialisés pour la MPOC n'étaient pas disponibles. Les patients furent évalués à leur entrée dans l'étude par un questionnaire médical et sociodémographique, leurs dossiers médicaux furent aussi consultés pour les visites à l'urgence, les hospitalisations et la durée de séjour reliée aux évènements respiratoires.

RÉSULTATS : Les effectifs comprenaient 96 sujets dans le groupe intervention et 50 sujets dans le groupe contrôle avec un âge moyen de 72 ans \pm 10.4 , un ratio $43 \mathrm{~F} / 53 \mathrm{H}$ dans le groupe intervention et de $28 \mathrm{~F} / 22 \mathrm{H}$ dans le groupe contrôle. Le VEMS moyen était à $46.4 \%$ de la valeur prédite dans le groupe Contrôle et de $41.2 \%$ dans le groupe Intervention. Les caractéristiques de base ne différaient pas entre les 2 groupes. Le nombre d'Hospitalisation (nb/sujet/an) fût réduit de façon substantielle dans les 12 mois pour le groupe intervention mais l'effet fût plus important chez la femme avec une réduction de 79\% ( $\mathrm{p}=.0001)$ alors que le programme chez l'homme a réduit le taux d'hospitalisation de $31 \%(\mathrm{p}=.007)$. Pour le groupe contrôle on enregistrait une diminution de $20 \%$ ( $p=n s)$ chez la femme et de $34 \%(p=.01)$ chez l'homme. Le programme n'a pas eu d'impact sur le nombre de visite à l'urgence.

CONCLUSION : Un programme de soins intégrés pour la clientèle MPOC entraîne une diminution du nombre d'hospitalisations surtout chez les femmes.

\section{0}

\section{CHANGEMENTS PHÉNOTYPIQUES OBSERVÉS CHEZ DES CELLULES DENDRITIQUES DE SOURIS EXPOSÉES À SACCHAROPOLYSPORA RECTIVIRGULA}

A Demanche, M Girard, M-J Beaulieu, E Israel-Assayag, Y Cormier Centre de Recherche de I'Hôpital Laval, Québec, Québec, Canada Lalvéolite allergique extrinsèque (AAE) est une maladie pulmonaire inflammatoire caractérisée par une réponse immune exagérée et une infiltration lymphocytaire dans les poumons. Peu d'études se sont attardées au rôle des cellules dendritiques dans le développement de cette lymphocytose. Cette étude a été réalisée afin de vérifier si l'exposition à Saccharopolyspora rectivirgula (SR), le principal agent responsable de l'AAE au Canada, pouvait influencer le phénotype et les fonctions des cellules dendritiques.

MÉTHODE: Des cellules dendritiques obtenues de la moelle de souris 
C57BL/6 après culture avec de l'IL-4 et du GMC-SF ont été stimulées avec du LPS ou du SR. La pureté et la maturation des cellules furent vérifiées par cytométrie. L'expression des TLRs a été quantifiée par RT-PCR. L'activité enzymatique de l'indoleamine 2,3-dioxygénase (IDO) à été mesurée par HPLC.

RÉSULTATS: 95\% de cellules dendritiques CD11c+ sont obtenues suite à la culture. Le LPS et le SR induisent la maturation des cellules de $98 \%$ et 95\% respectivement. La stimulation au SR induit une diminution moyenne de 40\% des ARNm des TLRs 3,5,6,9, ce qui n'était pas observé avec le LPS. Une exposition au SR ou au LPS active l'IDO et induit la synthèse de 5,8 et $9,5 \mu \mathrm{m}$ de kynurénine.

CONCLUSION: Le SR induit la maturation des cellules dendritiques dans une proportion similaire au LPS. L'exposition au SR induit une expression différentielle des TLRs qui semble spécifique à cet antigène. Les cellules stimulées expriment activement l'IDO qui peut empêcher la prolifération des lymphocytes. Ces changements subis par les cellules dendritiques pourraient influencer leur dialogue avec les lymphocytes $\mathrm{T}$.

\section{1}

\section{L'UTILISATION DE L'ÉCHO-ENDOSCOPIE} OESOPHAGIENNE (ÉEO) POUR L'INVESTIGATION DES CARCINOMES PULMONAIRES EN CENTRE UNIVERSITAIRE

P Trân'1, G Rateb², R Boileau' ${ }^{1}$, N Bouchard ${ }^{1}$

${ }^{1}$ Département de médecine, services de pneumologie et de 2gastroentérologie

CONTEXTE : L'écho-endoscopie oesophagienne avec cytoponction est une modalité diagnostique peu invasive pour le diagnostic et le staging des carcinomes pulmonaires. L'impact clinique de cette méthode d'investigation n'a été que peu étudié.

OBJECTIF : Décrire l'utilisation de l'ÉEO dans l'investigation du cancer pulmonaire dans un centre universitaire : (1) sa valeur dans le diagnostic et le staging et (2) les complications associées.

MÉTHODE : Une analyse rétrospective de tous les cas référés pour cet examen dans un contexte de carcinome pulmonaire au CHUS de mars 2006 à juillet 2008 a été effectuée.

RÉSULTATS : 28 patients ont été inclus, dont 17 référés sans diagnostic histologique préalable. De ces derniers, 13 ont eu une ÉEO qui a confirmé le diagnostic histologique, soit par ponction au médiastin (tumeur ou adénopathie), au foie ou à la surrénale gauche. Une atteinte médiastinale était suspectée à l'imagerie chez 22 patients et confirmée par cytoponction dans 13 cas (soit à la fenêtre aorto-pulmonaire, en sous-carénal ou en paraœsophagien). Cinq patients ont également eu une médiastinoscopie non diagnostique et l'ÉEO a démontré l'atteinte médiastinale dans un de ces cas. Aucune complication majeure, mais 4 complications mineures ont été rapportées ( 3 cas de douleur à la gorge, 1 cas d'hypopnée transitoire due à la sédation).

CONCLUSION : L'écho-endoscopie oesophagienne permet de prouver de façon peu invasive une atteinte surrénalienne gauche, médiastinale ou hépatique et ainsi, diminuer le nombre d'explorations chirurgicales. Il s'agit d'une modalité sécuritaire pour l'investigation du cancer pulmonaire qui pourrait ainsi être utilisée davantage.

\section{2}

\section{PROGRESSION OF RESPIRATORY SYMPTOMS IN A PROSPECTIVE COHORT OF APPRENTICES IN CONSTRUCTION WORK}

F Rodier ${ }^{1}$, J-L Malo ${ }^{2}$, H Ghezzo ${ }^{2}$, D Gautrin ${ }^{2}$

${ }^{1}$ McGill University, Montreal, ${ }^{2}$ Axe de recherche en santé respiratoire, Hôpital du Sacré-Cœur de Montréal, Montréal, Quebec

BACKGROUND: Construction workers are exposed to large amounts of dust and irritants.

OBJECTIVES: To characterize, the progression of respiratory symptoms in susceptible individuals who begin vocational training in carpentry, plasterering or plumbing Methods: We recruited a cohort of 148 students who enrolled in one of these programs at a school offering training in construction work. In this longitudinal study, subjects were evaluated at beginning and end of training (14 months duration); 124(83.7\%) subjects participated to the follow-up assessment. A questionnaire, spirometry and methacholine bronchial challenge were administered at the first and second visit.

RESULTS: Among the 124 apprentices, 37 had probable asthma at inception based on asthma symptoms, physician diagnosis or $\mathrm{PC}_{20}$ less than $16 \mathrm{mg} / \mathrm{ml}$ (risk index). Nine subjects $(24.3 \%)$ with probable asthma at baseline, compared to $6(7,0 \%)$ without, experienced worsening of respiratory symptoms with an odds ratio (OR, 95\% CI) of 4.2 (1.4-13). Numbers of specific respiratory symptoms reported in the different trades were 1 or more symptoms and 2 or more symptoms as follows: Carpenters 13/48 and $8 / 48$, plasterers $7 / 24$ and $1 / 24$, and plumbers $4 / 42$ and $1 / 42$, respectively. One symptom at work was reported by $8 / 37$ subjects with probable asthma at baseline compared to $1 / 87$ in the non asthmatic group. Wheezing, dyspnea and expectoration tended to persist at visit 2 .

CONCLUSION: Our study showed that worsening of symptoms occurred primarily in the susceptible group; however, new symptoms were less frequent. Symptoms at work were not common possibly due to underreporting or too short follow-up period.

\section{3}

\section{CARACTÉRISATION DES CELLULES SATELLITES MUSCULAIRES PROVENANT DE PATIENTS AYANT UNE MALADIE PULMONAIRE OBSTRUCTIVE CHRONIQUE (MPOC)}

M-E Thériault, M-A Caron, M-E Paré, F Maltais, R Debigaré Centre de recherche, Hôpital Laval, Institut universitaire de cardiologie et de pneumologie de I'Université Laval

La maladie pulmonaire obstructive chronique (MPOC) est caractérisée par une obstruction bronchique irréversible et progressive. L'atrophie musculaire périphérique est fréquente dans la MPOC et a un impact négatif sur la qualité de vie et la survie des sujets atteints. Un déficit dans la régénération du tissu musculaire, qui est du ressort des cellules satellites, pourrait contribuer au développement de l'atrophie musculaire mais n'a jamais été évalué chez ces sujets. Un nombre insuffisant de cellules satellites combiné à un processus de régénération déficient pourrait altérer la capacité du tissu musculaire à récupérer adéquatement suite à un dommage musculaire. Nous proposons l'hypothèse que le potentiel de régénération est déficient chez les patients ayant une MPOC comparativement à des sujets sains d'âge similaire. Afin de tester notre hypothèse, nous avons développé un modèle de culture primaires de cellules satellites provenant de biopsies musculaires de sujets ayant ou non une MPOC afin de: 1) quantifier le nombre de cellules satellites présentes dans chaque biopsie; 2) d'évaluer leur potentiel de régénération en testant leur capacité à proliférer et; 3 ) à se différencier en myotubes. Jusqu'à maintenant, nous avons démontré la faisabilité de la culture primaire de cellules musculaires provenant de sujets ayant une MPOC. De plus, un marquage positif pour Pax-7, la présence de la Myosin Heavy Chain et l'induction d'Atrogin-1 et MuRF-1 sont tous des indicateurs confirmant la nature musculaire de ces cellules. Ce projet permettra pour la première fois de caractériser les cellules satellites musculaires de patients ayant une MPOC et d'évaluer leur potentiel régénératif.

\section{4}

\section{NEONATAL INTERMITTENT HYPOXIA ALTERS INSPORATORY AND SYMPATHETIC NERVE RESPONSES TO HYPOXIA IN ADULT MALE RATS}

C Julien, R Kinkead, A Bairam, V Joseph

Department of Pediatrics, Centre de recherche de l'Hôpital St

François d'Assise, Québec, Québec

We have recently shown that neonatal intermittent hypoxia (NIH - associated to apnea in preterm neonates) disrupts the development of the respiratory control system, and enhances apnea frequency in newborn rats. Because, neonatal conditions such as NIH may have long-term consequences, we tested the hypothesis that it alters cardio-respiratory functions in adult rats. Male rat pups were exposed to $\mathrm{NIH}\left(5 \% \mathrm{O}_{2}\right.$, every $6 \mathrm{~min}$ for $1 \mathrm{~h}$ followed by $1 \mathrm{~h}$ normoxia, 24h/day, postnatal days 3-12) or air (CONT). Anesthetized, ventilated and vagotomized adult rats (90-120 
day-old) were used to measure mean blood pressure (MBP) and activity of phrenic and sympathetic (splanchnic) nerves, under baseline conditions and 1 hour after 10 successive hypoxic episodes $\left(12 \% \mathrm{O}_{2}\right)$ used to mimic arterial oxygen desaturation as occurring in sleep apneas. Under baseline conditions, NIH rats had higher MBP than CONT ( $92 \pm 4$ vs. $83 \pm 4 \mathrm{mmHg}$ ). During recovery, MBP decreased progressively in NIH rats $(-9 \mathrm{mmHg})$, and remained stable in CONT $(+2 \mathrm{mmHg})$, while splanchnic nerve activity remained stable in CONT rats $(+21 \pm 14 \%)$, but drastically decreased in $\mathrm{NIH}$ rats $(-41 \pm 9 \%)$. During the same period phrenic nerve activity increased in CONT $(+75 \pm 26 \%$ - reflecting respiratory long-term facilitation) but remained unaltered in $\mathrm{NIH}$ rats $(-3 \pm 18 \%)$. In summary, $\mathrm{NIH}$ rats are hypertensive and have an impaired cardio-respiratory regulation in response to repeated hypoxic episodes as adults. We conclude that cardiorespiratory morbidity in adults is linked to adverse neonatal conditions such as intermittent hypoxia.

Funded by programme de formation RSR-FRSQ; Sick Kids Foundation (grant \#XG07-006).

\section{5}

\section{IMPACT DU STRESS OXYDANT ET DES GLUCOCORTICOÏDES SUR LES MÉCANISMES DE RÉPARATION DES LÉSIONS DE L'ÉPITHÉLIUM ALVÉOLAIRE EN CULTURE PRIMAIRE \\ C Chupin, A Privé, E Brochiero, Y Berthiaume CRCHUM, Dpt de Médecine, UdM}

Le syndrome de détresse respiratoire aiguë (SDRA), présente initialement un processus inflammatoire entraînant des lésions des cellules pulmonaires. Cliniquement, ce processus mène à la formation d'un œdème à haute perméabilité. La réparation des lésions épithéliales est un processus complexe, impliquant les mécanismes d'étalement, de migration, de prolifération et de différentiation épithéliale. L'impact du stress oxydant et des traitements anti-inflammatoires sur ces mécanismes étant encore mal connu, nous les avons documentés dans un modèle in vitro. Des cellules épithéliales alvéolaires de type II sont cultivées en culture primaire, en présence de bléomycine $(12,5-150 \mathrm{mU} / \mathrm{ml})$. Cet oxydant inhibe la fermeture des plaies de façon temps et concentration dépendants $(\mathrm{p}<0,0001)$. Il inhibe aussi la migration $(\mathrm{p}<0,0001)$ et la prolifération $(\mathrm{p}<0,0001)$ cellulaire. Les glucocorticoïdes sont considérés comme des agents thérapeutiques chez les patients souffrant de SDRA. Leur utilisation est cependant sujette à forte controverse. Notre étude montre que le dexaméthasone (100nM) inhibe la fermeture des plaies $(41,01 \%, 24 \mathrm{~h} ; 9,46 \%, 48 \mathrm{~h})$. De plus, le dexamethasone, en présence de bléomycine, accentue l'inhibition du processus de fermeture des plaies due à la bléomycine $(64,24 \%, 24 \mathrm{~h} ; 69,92 \%, 48 \mathrm{~h})$. Dans notre modèle, le stress oxydant, semble avoir un effet néfaste sur les processus de réparation. De plus, la présence de dexamethasone semble amplifier l'effet néfaste du stress oxydant sur le processus de réparation. Ces résultats pourraient en partie expliquer l'absence d'effet bénéfique des glucocorticoïdes dans le traitement du SDRA.

Supported by RSR-FRSQ, FCFK, IRSC.

\section{6}

\section{LES CELLULES T RÉGULATRICES DANS L'ALVÉOLITE} ALLERGIQUE EXTRINSÈQUE

\section{Girard, E Israël-Assayag, Y Cormier}

\section{Centre de recherche de l'Hôpital Laval}

INTRODUCTION : Une minorité d'individus exposés à un agent pouvant induire l'AAE développe la maladie. Des études antérieures ont démontré que, chez la souris, une infection au virus Sendai est nécessaire pour déclencher la maladie causée par l'inhalation d'antigène de la bactérie Saccharopolyspora rectivirgula (SR). Les mécanismes impliqués dans cette tolérance sont incompris de même que les mécanismes expliquant le déséquilibre de la réponse immune à la suite d'une infection virale. Les cellules $\mathrm{T}$ régulatrices $(\mathrm{Tr})$ qui, jouent un rôle crucial dans la maintenance de l'homéostasie de la réponse immune en inhibant la prolifération des cellules T pourraient être impliquées dans la pathophysiologie de l'AAE. MÉTHODE : 4 groupes de souris ont été étudiées. Gr. 1 : instillations intranasales (i.n.) de saline. Gr. 2 : i.n. de SR. Gr. 3 : i.n. de saline et une i.n. du virus Sendai à la semaine 3. Gr. 4 : i.n. de SR et une i.n. de virus Sendai à la semaine 3. Les i.n. de saline et de SR ont été réalisées 3 fois par semaine pendant 12 semaines. Suite aux sacrifices, des lavages bronchoalvéolaires ont été effectués, les poumons récoltés et les Tr isolés.

RÉSULTATS : Les Tr des souris exposées au SR suppriment la prolifération des cellules $\mathrm{T}$ à $62,6 \%$. La synergie entre l'antigène et le virus altère les fonctions des Tr qui ont perdu la capacité d'inhiber la prolifération des cellules T effectrices.

CONCLUSION : Chez la souris, les Tr semblent impliquées dans la tolérance à l'antigène SR. Une infection virale concomitante à l'exposition au SR inhibe les fonctions des $\operatorname{Tr}$ qui ne peuvent plus contrôler cette réponse immune exacerbée provoquant une inflammation sévère.

\section{7}

\section{STRESS OXYDATIF ET TRANSPORT DE CHLORE DANS LES CELLULES FIBROSE KYSTIQUE}

MC Tessier, E Boncoeur, C Massé, Y Berthiaume

CRCHUM Hôtel-Dieu, Montréal, Quebec

L'atteinte des voies respiratoires est un facteur de morbidité et de mortalité chez les patients fibrose kystique (FK). L'inflammation, excessive et incontrôlée, serait à l'origine du stress oxydatif retrouvé au niveau des voies aériennes, et participerait à l'altération de la fonction pulmonaire. L'anomalie sous-jacente est une dérégulation du transport ionique, entrainant une diminution du liquide de surface, une déshydratation, et une mauvaise élimination du mucus. Notre étude vise à caractériser l'impact du stress oxydatif (DMNQ) sur la régulation des transports de chlore $\left(\mathrm{Cl}^{-}\right)$ dans des cellules FK et non-FK. Les efflux de $\mathrm{Cl}^{-}$, les courants ioniques totaux, CFTR, et autres Cl-ont été mesurés en chambre de Ussing avec et sans inhibiteur (CFTR172-NPPB). Tel démontré récemment (Cantin et al AJRCM, Jan 2007) on observe une diminution de l'expression (50\%) et de l'activité (20\%) du canal CFTR dans les cellules épithéliales non-FK traitées au DMNQ. Par contre, une augmentation $(1,75 \times)$ des efflux $\mathrm{Cl}^{-}$a été mise en évidence dans les cellules FK. Cette augmentation n'étant pas la conséquence de l'activation du canal CFTR, nous avons recherché des modulations dans l'expression des ARNm d'autres canaux $\mathrm{Cl}^{-}$. Nous avons observé par RT-PCR une augmentation $(2,5 \times)$ des ARNm de $\mathrm{ClC}_{2}$ dans les cellules $\mathrm{FK}$ et une légère diminution dans les cellules non-FK traitées au DMNQ. Cette observation est intéressante car chez la souris FK, le défaut de transport de $\mathrm{Cl}$ - associé à la dysfonction de CFTR serait compensé par une activité importante du canal $\mathrm{ClC}_{2}$. Il en résulterait l'absence de symptômes inflammatoires et lésionnels. Il est donc de grand intérêt de mieux comprendre comment le stress oxydant module les transports de chlore dans les cellules FK.

\section{8}

\section{ÉDUCATION AUX ASTHMATIQUES ET LE CONTRÔLE DE L'ASTHME - EXPÉRIENCE DU CHUM}

A Robay, Y Dubois, F Lasalle, F Malette, $C$ Bergeron

Centre Hospitalier de I'Université de Montréal

Plusieurs études ont démontré les effets bénéfiques de l'éducation aux asthmatiques adultes. La clientèle du CEA-CHUM est composé principalement de sujets atteints d'asthme modéré à sévère. Une enquête précédente avait démontré une très grande satisfaction envers le service de CEA-CHUM par la clientèle asthmatique. Toutefois, nous avons voulu déterminer l'efficacité de l'enseignement dans notre milieu. À l'aide d'un questionnaire téléphonique, nous avons réalisé une enquête chez les sujets ayant eu un enseignement entre octobre à décembre 2006. Les paramètres étudiés sont le contrôle de l'asthme selon le patient, le contrôle de l'asthme selon les critères de maîtrise, les exacerbations, l'utilisation du plan d'action, la prise de prednisone, les visites non prévues, les consultations à l'urgence et les hospitalisations, et ce pour l'année précédente et suivante à l'enseignement. Nous avons rejoint 26 patients. Parmi les sujets sondés, 96\% considérait leur asthme bien contrôlé et la bonne maîtrise de l'asthme selon les critères était de $81 \%$. Le nombre d'exacerbations a significativement diminué dans l'année suivant l'enseignement (156 vs 17, p = 0.0006), ainsi que l'utilisation du plan d'action (14 vs 4) et de la prednisone (23 vs 1 ). Après l'enseignement, il n'y a eu aucune visite à l'urgence ( 26 vs $0, \mathrm{p}=$ 
0.04), ni hospitalisation (3 vs 0 ). Cette enquête démontre que l'enseignement au CEA permet d'améliorer la maîtrise de l'asthme, de diminuer les exacerbations et les visites à l'urgence. Il est également fort intéressant de voir l'excellente corrélation entre l'estimation de la maîtrise de l'asthme par le patient et la correspondance avec les critères objectifs.

\section{9}

LEUCOTRIÈNES ET TRANSITION ÉPITHELIALE-

MÉSENCHYMATEUSE BRONCHIQUE - IMPLICATION DANS LA BRONCHIOLITE OBLITÉRANTE POST-GREFFE PULMONAIRE

S Ptaszynski, A Alrabea, V Arsenault, C Bergeron

Hôtel-Dieu du Centre Hospitalier de l'Université de Montréal

INTRODUCTION : La bronchiolite oblitérante (rejet chronique) est la principale cause de mortalité à long terme après une greffe pulmonaire. Cette pathologie est caractérisée par de l'inflammation et du remodelage dans les bronchioles. Certaines études ont rapporté un taux élevé de leucotriènes cysteinyl dans le liquide de lavage broncho-alvéolaire et le sang à la suite de greffes chez les animaux. Récemment, des effets pro-fibrotiques ont été attribués aux leucotriènes.

HYPOTHÈSE : Nous suggérons que les leucotriènes cysteinyl induisent la transition épithéliale-mesenchymateuse dans les cellules épithéliales bronchiques, ce qui participerait au développement du remodelage dans la bronchiolite oblitérante.

OBJECTIF : Étudier l'expression du collagène et de l'alpha-smooth muscle actine dans les cellules épithéliales en présence de LTC4.

MÉTHODE : La lignée cellulaire 16HBE a été stimulée par des doses croissantes de LTC4 $(1 \mathrm{ng} / \mathrm{ml}$ à $1000 \mathrm{ng} / \mathrm{ml})$ pour une période de $48 \mathrm{~h}$ avec un contrôle négatif (RPMI seul) et un contrôle positif (TGF-beta $10 \mathrm{ng} / \mathrm{ml}$ ). L'expression du collagène est mesurée au niveau de l'ARNm par RT-PCR.

RÉSULTATS : LTC4 augmente, de manière dose dépendante, l'expression du collagène IA1 (de 2.6 à 20.9X) et de l'alpha-smooth muscle actine (de 1.3 à $6.2 \mathrm{X}$ ) avec une réponse maximale à la dose de1000 ng/ml en comparaison au contrôle négatif. L'effet du LTC4 est supérieur à celui du TGFbeta (collagène IA1 : $5.3 \mathrm{X}$ et SMA : 2.7X).

CONCLUSIONS : Nos résultats démontrent que les leucotriènes cystényl peuvent stimuler l'expression de collagène et de l'alpha-smooth muscle actine dans les cellules épithéliales bronchiques et participer au processus de transition épithéliale.

\section{0}

\section{ORIGINE NEONATALE DU SYNDROME DE DESACCLIMATATION A L'HYPOXIE CHRONIQUE CHEZ LE RAT}

D Lumbroso, V Joseph

Département de pédiatrie,Université Laval, Centre de Recherche CHUQ, Hôpital Saint François d'Assise, 10 rue de l'espinay, Québec, Quebec, Canada

La maladie de Monge ou Mal Chronique des Montagnes (MCM) touche environ $4 \%$ des habitants de hautes altitudes ( $\geq 2500 \mathrm{~m}$ ). Ces symptômes sont bien caractérisés : une hypoxémie sévère, une érythrocytose excessive et dans certains cas une hypertension artérielle pulmonaire mais leurs origines restent encore méconnues. Notre hypothèse générale est qu'il existe une origine néonatale au MCM. Nous testerons cette hypothèse sur notre modèle expérimental, le rat. Nous exposons des rats en hypoxie chronique soutenue $\left(12 \% \mathrm{~d}^{\prime} \mathrm{O}_{2}\right)$ pendant les 10 premiers jours suivant leur naissance. A l'âge adulte, les animaux sont réexposés à l'hypoxie chronique pendant 14 jours. La réponse ventilatoire à l'hypoxie, le taux d'hémoglobine $[\mathrm{Hb}]$ et d'hématocrite (Hct) ainsi que la morphologie cardiaque sont étudiés. Les animaux mâles exposés à une hypoxie néonatale chronique $(\mathrm{n}=7)$ montrent une hypoventilation suite à l'exposition à l'hypoxie chronique par rapport aux contrôles $(58,2 \pm 1,9$ vs $68,3 \pm 3,1 \mathrm{ml} /$ $\mathrm{min} / 100 \mathrm{~g}, \mathrm{P}<0,05)$, une érythrocytose excessive $([\mathrm{Hb}]=237,6 \pm 1,6 \mathrm{vs}$ $224,6 \pm 2,7 \mathrm{~g} / \mathrm{dL} \mathrm{p}<0,01 ; \mathrm{Hct}=75,0 \pm 0,6$ vs $71,2 \pm 0,4 \% \mathrm{p}<0,01)$ et une hypertrophie du ventricule droit $(\mathrm{VD} /(\mathrm{VG}+\mathrm{VD})=40,4 \pm 0,8 \mathrm{vs}$ $27,9 \pm 0,1 \mathrm{p}<0,01)$. Ces résultats révèlent une désacclimatation à l'hypoxie chronique à l'âge adulte suite à une exposition à l'hypoxie chronique néonatale. Ils confirment donc l'hypothèse d'une origine néonatale du syndrome de désacclimatation à l'hypoxie chronique chez le rat adulte. L'hypoxie néonatale induit une altération de la réponse physiologique au niveau ventilatoire, hématologique et cardiovasculaire pulmonaire. Ceci suggère alors une origine néonatale au MCM chez l'homme.

\section{1}

\section{CARACTÉRISTIQUES DE LA FONCTION PULMONAIRE ET DE L'INFLAMMATION BRONCHIQUE CHEZ LES SUJETS ASTHMATIQUES ÂGÉS}

ME Ducharme ${ }^{1}$, P Prince ${ }^{1}$, N Hassan ${ }^{2}$, P Nair $^{2}$, LP Boulet ${ }^{1}$

${ }^{1}$ Centre de recherche de l'Hôpital Laval, Institut de cardiologie et de pneumologie de I'Université Laval, Québec (Québec), Canada ${ }^{2}$ McMaster University, Hamilton (Ontario), Canada

INTRODUCTION : L'asthme est fréquemment observé chez la personne âgée, affectant environ $7 \%$ des patients de 60 ans et plus. Chez cette population, l'asthme est souvent mal maîtrisé et résulte en une importante morbidité. Les caractéristiques de l'asthme des personnes âgées restent encore à être précisées afin d'optimiser le traitement et d'améliorer leur qualité de vie.

BUT : Comparer les anomalies de la fonction respiratoire et la présence de cellules inflammatoires dans l'expectoration induite chez les sujets asthmatiques jeunes et âgés.

MÉTHODES: Deux banques de données d'expectorations induites (Laval et McMaster) ont été analysées. Un groupe d'asthmatiques âgés de 60 à 72 ans $(n=85)$ a été comparé à un groupe de jeunes asthmatiques de 18 à 30 ans $(\mathrm{n}=135)$. Les débits expiratoires et les décomptes cellulaires d'expectoration induite ont été analysés.

RÉSULTATS : La fonction respiratoire des sujets âgés (VEMs : 70.1\%) était diminuée comparée aux asthmatiques jeunes (VEMs : $96.1 \%)(\mathrm{p}<0.0001)$. Une augmentation des neutrophiles a aussi été observée dans l'expectoration induite des sujets âgés $(67.7 \%)$ comparativement avec les jeunes asthmatiques $(35.8 \%)(\mathrm{p}<0.0001)$. Il n'y a pas de corrélation entre le VEMs et le taux de neutrophiles dans l'expectoration induite.

CONCLUSION : Les sujets asthmatiques âgés présentaient un phénotype d'asthme différent des sujets asthmatiques jeunes. L'obstruction bronchique associée à l'asthme était plus sévère chez la personne âgée que chez le patient plus jeune.

\section{2}

\section{CARACTÉRISTIQUES DE LA RÉPONSE VENTILATOIRE À L'ĖPIBATIDINE CHEZ LE RAT EN DÉVELOPPEMENT}

LM Niane, V Joseph, A Bairam

Département de Pédiatrie, Centre de recherche de l'Hôpital St François

INTRODUCTION: Les corps carotidiens sont les principaux senseurs périphériques de l'oxygène dans le contrôle de la ventilation. Ils présentent une augmentation graduelle de leur chémosensibilité durant la période néonatale. L'acétylcholine est l'un des principaux neurotransmetteurs de l'hypoxie au niveau des corps carotidiens chez l'adulte mais son rôle chez le nouveau-né reste mal défini. Notre hypothèse est que la transmission cholinergique est immature chez le nouveau-né et la fonctionnalité des récepteurs cholinergiques nicotiniques est âge dépendante.

METHODE: L'effet de l'épibatidine, un puissant agoniste nicotinique exclusivement périphérique a été étudié. A partir d'une courbe doseréponse chez le rat adulte, la dose de $5 \mathrm{ug} / \mathrm{Kg} \mathrm{IP}$, induisant une stimulation maximale de la fréquence respiratoire a été choisie. La fréquence respiratoire (Fr), le volume courant (VT), la ventilation minute (VE) ont donc été mesurés par pléthysmographie chez des rats nouveaux-nés âgés de 1, 4, 7,12 et 21 jours postnataux après injection d'épibatidine.

RESULTATS: Chez les ratons l'épibatidine stimule significativement la fréquence respiratoire quelque soit l'âge. Cette augmentation est de $+4 \%,+21 \%,+30 \%,+40 \%$, et $+43 \%$ pour $1,4,7,12$ et 21 jours (ANOVA, $\mathrm{p}<0.0001$ ), respectivement.

CONCLUSION: Ces résultats montrent que la réponse ventilatoire à l'épibatidine est âge dépendante. Ils suggèrent ainsi que les récepteurs 
nicotiniques sont exprimés dans le corps carotidien du rat nouveau-né et ils jouent un rôle dans la maturation fonctionnelle des chémorécepteurs carotidiens en période postnatale.

Remerciements : PFRSRQ, Sick Kids Foundation, Fondation des étoiles, IRSC

\section{3}

CC FAMILY CHEMOKINE RECEPTOR 2 (CCR2) IS INVOLVED IN THE PATHOGENESIS OF MUSCLE DEGENERATION IN THE DYSTROPHIC DIAPHRAGM

F Liang, G Danialou, A Maniakas, S Yim, J Bourdon, BJ Petrof Meakins-Christie Labs, MUHC Research Institute, and Respiratory Division, McGill University

INTRODUCTION: Duchenne Muscular Dystrophy (DMD) is a form of muscular dystrophy characterized by progressive degeneration of the diaphragm, with consequent respiratory muscle failure. The inflammatory response found within dystrophic muscles promotes the pathology of DMD. Chemokines are small cytokines which act as chemoattractants for different inflammatory cell types. We have previously reported that several chemokines of the CC class, which attract macrophages in particular, are highly upregulated in the skeletal muscles of dystrophic $(\mathrm{mdx})$ mice, a model of DMD.

PURPOSE: To determine whether genetic ablation of CCR2, a CC class chemokine receptor, is able to attenuate pathological changes within the dystrophic diaphragm and other skeletal muscles of mdx mice.

METHODS AND RESULTS: Mdx mice were genetically crossed with CCR2-1- knockout mice and evaluated at 2 ages ( 6 weeks and 3 months). Histological analysis revealed that $\mathrm{mdx} / \mathrm{CCR} 2-1-$ myofibers had significantly fewer central nuclei than their mdx counterparts (54\% vs. $66 \%$ ) in the tibialis anterior, suggesting reduced antecedent myofiber necrosis. By quantitative RT-PCR, multiple immune genes were either upregulated (CCL3, CCL5, CCL8, CCR10, CCL12, CCL19, IL8rb, SPP1) or downregulated (CCL4, IL15) in mdx/CCR2-/- muscles. Most importantly, diaphragmatic force production was significantly increased by approximately $50 \%$ in $\mathrm{mdx} / \mathrm{CCR} 2-1-$ compared to $\mathrm{mdx}$ mice at both 6 weeks and 3 months of age.

CONCLUSIONS: These findings indicate that CCR2 plays a significant role in promoting the progression of muscle pathology in the dystrophic diaphragm, and suggest that CCR2 and/or its ligands could be useful therapeutic targets in DMD.

Supported by: CIHR, FRSQ, MUHC Research Institute

\section{4}

EXPLORING ANTI-INFLAMMATORY AND ANTIBACTERIAL EFFECTS OF PRESSURIZED WHEY PROTEIN IN A MURINE MODEL OF CHRONIC LUNG INFECTION WITH PSEUDOMONAS AERUGINOSA

Osama Kishta, Michele Iskandar, Larry Lands McGill University and Montreal Children's hospital

$P$. Aeruginosa is a ubiquitous gram-negative pathogen commonly responsible for chronic respiratory infections in ventilated or immunocompromised patients such as neutropenic patients and patients with HIV. Cystic Fibrosis (CF) patients are frequently vulnerable to infection with this pathogen due to their viscous and dehydrated mucus and impaired mucociliary clearance. P. aeruginosa causes oxidative stress in animal models of lung infection. Whey protein is a natural by-product of cheese production known to contain biologically active peptides. Some of these peptides have been reported to enhance both phagocytosis by human monocytes and oxidative metabolism of the respiratory burst in human and rat neutrophils. Whether this anti-microbial effect of whey-derived peptides functions in vivo in enhancing host resistance to lung infection is still unknown. Whey protein is also rich in sulfhydryl $(\mathrm{SH})$ groups, which are also expected to indirectly enhance neutrophil phagocytic function by protecting them from pathogen-mediated and/or respiratory burst-associated oxidative stress. Hyperbaric pressure treatment of whey enhances its digestibility thereby releasing biologically active peptides and free $\mathrm{SH}$-groups. This would enhance the anti-bacterial and anti-inflammatory effect of pressurized whey protein compared to its native counterpart. Pressurization of whey protein enhanced its ability to suppress LPSstimulated IL-8 secretion by respiratory epithelial cells.

HYPOTHESIS: We hypothesize that introduction of pressurized whey protein as a protein source in murine diet for 1 month prior to infection with $P$. aeruginos $a$ will attenuate the inflammatory response and improve bacterial clearance.

METHODS: We used a non-surgical method to infect female C57BL/6 mice in our time course study and found that a bacterial dose of $8 \times 10^{5} \mathrm{CFUs} /$ mouse induced a prominent inflammation with $97.3 \%$ survival rate. Two groups of mice were randomized to semi-purified diets containing either native or pressurized whey as a protein source in their diets for 4 weeks. 3 days post-infection with $P$. aeruginosa lung bacterial burden and inflammatory indices (weight loss, total and differential leukocyte count in BAL fluid) were studied.

PRELIMINARY RESULTS: Lung bacterial burden was 5-fold less in pressurized whey-fed group compared to native whey-fed group (medians: 125200 and $647500 \mathrm{CFUs} /$ lung, $\mathrm{N}=9$ and 8, respectively). This difference was not statistically significant. Weight loss and inflammatory cells in lung lavage were not different between the groups.

FUTURE DIRECTION: More animals will be fed whey, pressurized whey or a casein-based diet and studied post-infection with P. aeruginosa. If the level of lung bacterial burden is consistently and significantly shown to be less in the pressurized whey group, phagocytic function of macrophages and neutrophils will be assessed.

Funded by CCFF, Sick Kids Foundation and FRSQ studentship.

\section{5}

\section{INFLUENCE DE L'ÉPITHÉLIUM SUR LES PROPRIÉTÉS CONTRACTILES ET PROLIFÉRATIVES DU MUSCLE LISSE BRONCHIQUE}

PA Risse, T Jo, MC Michoud, P Ferraro, B Tolloczko, JG Martin Laboratoires Meakins-Christie, Université McGill, Montréal; Hôpital Notre Dame, Université de Montréal, Montreal, Quebec INTRODUCTION : Dans les voies aériennes, la proximité anatomique de l'épithélium et du muscle lisse suggère des interactions qui restent cependant peu connues et difficiles à étudier. L'objectif de ce travail a été de mettre au point un model humain in vitro de cellules musculaires lisses (CML) et de cellules épithéliales en co-culture afin de comprendre l'influence de l'épithélium sur la contractilité et la prolifération des CMLs bronchique.

MÉTHODES : les expériences ont été réalisées à partir de cultures primaires de CMLs bronchiques humaines et d'une lignée de cellules épithéliale bronchique humaine (Beas-2B) cultivées en interface air-liquide. Après 24 heures de co-culture, la capacité contractile des CMLs a été évaluée en mesurant le signal calcique intracellulaire induit par à un $1 \mu \mathrm{M}$ d'histamine, à l'aide d'une sonde radiométrique (Fura-2). La prolifération des CMLs a été quantifiée en mesurant par cymomètre de flux l'incorporation de bromodeoxyuridine, durant 18 heures de co-culture.

RÉSULTATS : le signal calcique en réponse à l'histamine a été significativement réduit lorsque les CMLs étaient co-cultivées en présence de cellules épithéliales. D'autre part, la présence de cellules épithéliales a induit une augmentation de la prolifération des CMLs qui a pu être bloquée par un inhibiteur du récepteur à l'epidermal growth factor a été associée à une augmentation de la concentration en heparin-binding EGF-like growth factor (HB-EGF) dans les surnageants.

CONCLUSIONS : Dans notre modèle, les cellules épithéliales exercent un effet inhibiteur sur la réactivité des CMLs associé à une augmentation de la prolifération, potentiellement induit par la sécrétion d'HB-EGF. 
36

EFFETS DE L'INSPIRATION PROFONDE ET DE L'HYPERVENTILATION EUCAPNIQUE SUR LA RÉPONSE À LA MÉTACHOLINE CHEZ L'ATHLÈTE

E Blouin, V Bougault, J Turmel, L-P Boulet

Centre de recherche de I'Hôpital Laval, Institut de cardiologie et de pneumologie de I'Université Laval, Québec (Québec), Canada

INTRODUCTION : La provocation bronchique à la métacholine (PM) et l'hyperventilation eucapnique (HVE) sont des tests couramment utilisés pour évaluer la réactivité bronchique chez l'athlète. L'absence d'inspirations profondes (IP) préalablement à une PM entraîne une chute plus importante du VEMS chez des individus normaux, mais cette réponse est inchangée chez les asthmatiques et les personnes obèses. Cependant, l'influence de ces procédures n'a pas encore été démontrée chez une population d'athlètes.

OBJECTIF : Évaluer les effets de l'HVE et de l'absence d'IP sur la réponse à la métacholine chez l'athlète de haut niveau.

MÉTHODES : Quatre PM (deux «standard » : précédée (test A) ou non (test B) de l'HVE; et deux à dose unique : précédée (test D) ou non (test C) d'une période de 20 minutes sans IP) ont été effectuées chez 6 sujets témoins (âge : $23 \pm 4$ ans) et 12 athlètes (âge : $25 \pm 5$ ans).

RÉSULTATS : Concernant l'effet de l'HVE sur la réponse à la métacholine, la CP20 (moyenne géométrique [étendue]) était de 27,8 mg/mL $(4,3$ - >128) et 23,8 mg/mL (7,2 - >128) ( p >0,05) chez les témoins et de 39,9 $\mathrm{mg} / \mathrm{mL}(3,5->128)$ et $51,7 \mathrm{mg} / \mathrm{mL}(5,8->128)(\mathrm{p}=0,02)$ chez les athlètes pour les tests $\mathrm{A}$ et $\mathrm{B}$ respectivement. En ce qui a trait à l'effet de l'absence d'IP, le \% moyen de chute du VEMS aux tests $C$ et $D$ était de $11,8 \%$ et $19,2 \%(\mathrm{p}=0,02)$ chez les témoins et $13,5 \%$ et $25,5 \%(\mathrm{p}=0,02)$ chez les athlètes.

CONCLUSION : L'HVE augmente légèrement la réponse à la métacholine chez les athlètes alors qu'elle n'influence pas significativement celle des témoins. D'un autre côté, l'absence d'IP augmente la réponse à la métacholine de façon similaire chez les deux groupes.

\section{7}

\section{MESURE DE L'HYPERINFLATION DYNAMIQUE CHEZ LES PATIENTS AYANT UNE MALADIE PULMONAIRE OBSTRUCTIVE CHRONIQUE: COMPARAISON ENTRE L'ÉPREUVE D'EFFORT À CHARGE CONSTANTE ET À CHARGE PROGRESSIVE}

\section{Minville, D Saey, F Maltais}

Centre de recherche, Hôpital Laval, Université Laval, Québec INTRODUCTION: L'hyperinflation dynamique (HD) est une variable importante dans la limitation de la tolérance à l'effort chez les patients ayant une maladie pulmonaire obstructive chronique (MPOC). L'objectif de cette étude était de comparer le degré d'HD obtenu au cours de deux épreuves d'effort sur ergocycle; l'une à charge progressive (EECP) et l'autre à charge constante (EECC). L'équivalence dans la mesure de l'HD entre ces deux tests reste actuellement à établir.

MÉTHODOLOGIE: Dix patients avec MPOC ont effectué 2 EECP et 1 EECC réalisée à $80 \%$ de la charge maximale atteinte. L'ordre entre la deuxième EECP et l'EECC a été randomisé. La capacité inspiratoire (CI), la consommation d'oxygène (VO2), la ventilation (VE) et la dyspnée sur l'échelle de Borg ont été mesurées au repos et à l'effort maximal.

RÉSULTATS: Une réduction significative de la CI à l'effort a été observée dans les 2 types de tests. Aucune différence significative n'a été notée entre la baisse de la CI lors de l'EECP et de l'EECC (750 $\pm 280 \mathrm{~mL}$ vs $700 \pm 440 \mathrm{~mL}$; moyenne $\pm \mathrm{DS} ;-27 \%$ vs $-25 \%$ respectivement; $\mathrm{p}=0,72$ ) ni pour les autres variables en fin d'effort (VO2 $(1,4 \pm 0,3$ vs $1,4 \pm 0,4 \mathrm{~L} /$ min; $\mathrm{p}=0,79) ; \mathrm{VE}(47,5 \pm 10,9$ vs $48,5 \pm 11,5 \mathrm{~L} / \mathrm{min} ; \mathrm{p}=0,78)$; dyspnée $($ Borg $=8,0 \pm 1,8$ vs $7,5 \pm 2,0 ; p=0,39)$ ). Finalement, il n'y avait pas de différence significative entre les première et deuxième EECP, ni pour la diminution de la CI $(890 \pm 430 \mathrm{~mL}$ vs $750 \pm 280 \mathrm{~mL} ;-34 \%$ vs $-32 \%$ respectivement; $\mathrm{p}=0,22$ ), ni pour les autres variables mesurées. CONCLUSION: Cette étude suggère que l'HD mesurée lors d'une EECP et d'une EECC est comparable, et que les EECP démontrent une bonne reproductibilité entre elles.

\section{8}

PROTOLLIN INHIBITS THE DEVELOPMENT OF ALLERGIC ASTHMA IN A MOUSE MODEL VIA EFFECTS ON THE NASAL-ASSOCIATED LYMPHOID TISSUE

KH Shalaby, T Jo, Y Wang, C Rioux, JG Martin

Meakins-Christie Laboratories, McGill University, Montréal; GlaxoSmithKline Biologicals North America, Laval, QC, Canada

RATIONALE: Controlling the inflammatory response to an allergen by modulating the innate immune system may be a therapeutic option in asthma. We have found that BALB/c mice sensitized to a birch tree pollen extract (BPEx) and subsequently treated intranasally with Protollin ${ }^{\mathrm{TM}}$ had significant inhibition of airway hyperresponsiveness (AHR), bronchoalveolar lavage (BAL) neutrophilia and serum IgE levels after allergen challenge. Protollin consists of toll-like receptor 2 and 4 agonists. We sought to examine the immediate effects of Protollin on the nasal-associated lymphoid tissue (NALT) and determine Protollin's modulation of BAL, as well as, splenocyte-derived cytokines.

METHODS: Balb/c mice sensitized to BPEx received either intranasal PBS, BPEx, Protollin-adjuvanted BPEx (Pro/BPEx), or Protollin alone (Pro). NALT was harvested for mRNA extraction and splenocytes were restimulated with BPEx in culture to assess cytokine levels in the supernatants. BAL supernatants were assayed by a cytokine multiplex, following BPEx challenge of mice treated with PBS, BPEx, Pro/BPEx, or Pro.

RESULTS: Intranasal Protollin downregulated the expression of GATA-3 and T-bet, the Th2 and Th1 'master transcription factors' in the NALT. IL-10 expression tended to be higher as a result of Pro- compared to PBStreatment. The neutrophil chemokine KC, as well as, IL-4 and IL-5 protein levels were significantly inhibited in BAL supernatants of Pro/BPEx or Pro-treated mice. Compared to splenocytes harvested from PBS-treated mice, those from Pro/BPEx, or Pro-treated animals produced increased protein levels of interleukin (IL)-10, IL-13 and interferon- $\gamma$ in response to allergen restimulation. However, Protollin's inhibition of AHR was not affected by monoclonal antibody neutralization of IL-10 in vivo.

CONCLUSIONS: Protollin has an immunomodulatory effect mediated via the NALT that prevents experimental allergic asthma in mice and that appears to be IL-10-independent.

Funded by: Canadian Thoracic Society, CIHR, J.T. Costello Memorial Research Fund, QRHTP

\section{9}

\section{EFFETS PHYSIOLOGIQUES DE L'INHIBITION COMBINÉE DES CYCLOOXYGÉNASES (COX) ET DE L'ÉPOXYDE HYDROLASE SOLUBLE (SEH) SUR LA RÉACTIVITÉ DES BRONCHES}

D Serrano, C Morin, S Pelloux, É Rousseau

Département de physiologie et biophysique, FMSS, Université de Sherbrooke

Le statut inflammatoire de la paroi des bronches affecte leur propre réactivité aux agents pharmacologiques et aux lipides bioactifs. En conséquence nous avons limité la production des prostaglandines et augmenté le temps de demi-vie des époxy-éïcosanoïdes anti-inflammatoires. Il a été démontré que ces dérivés de la voie de l'acide arachidonique sont impliqués dans le contrôle de la réactivité des muscles lisses des voies respiratoires (MLVR) (Morin C. et al. 2007, 2008). Le but de cette étude était d'évaluer les implications fonctionnelles de différents inhibiteurs enzymatiques sur la réactivité des bronches en réponse à la méthacholine $(\mathrm{MCh})$ et aux acides époxy éícosatriénoïques (EET). L'indométhacine et l'acide uréido-dodécanoïque adamantyl (AUDA) ont été utilisées comme inhibiteurs respectifs des COX et de la sEH et ce de façon combinée sur les MLVR natifs et mis en culture. Des immunobuvardages et des mesures de tension isométrique on été réalisés. La sEH qui est connue pour dégrader les EET, a été détectée dans les fractions cytosoliques des MLVR de cobaye et chez l'humain. Suite à l'inhibition des COX et de la sEH, une augmentation de la contraction muscarinique a été mesurée et des effets relaxants plus importants ont été quantifiés pour les EET sur les trachées de cobaye natives par rapport à celles mises en culture pendant 3 jours. Par ailleurs, des bronchioles humaines distales prétraitées avec l'AUDA démontrent 
une relaxation plus marquée aux EET. En conséquence, l'inhibition enzymatique des COX et de la sEH, augmente les relaxations aux EET des explants bronchiques natifs et cultivés dérivés des trachées de cobaye et des bronchioles humaines

\section{0}

\section{EXCLUSION OF THE H-2K HAPLOTYPE AS A HOST SUSCEPTIBILITY LOCUS FOR PROGRESSIVE CRYPTOCOCCAL PNEUMONIA USING CONGENIC C57BL/6J MICE}

S Carroll ${ }^{1,2}$, JC Loredo Osti ${ }^{3}, K_{\text {Morgan }}{ }^{1,2}$, S Qureshi ${ }^{1,2}$

${ }^{1}$ McGill University, Montreal, QC, Canada, ${ }^{2}$ McGill Centre for the Study of Host Resistance, Montreal, QC, Canada, ${ }^{3}$ Department of Mathematics and Statistics, Memorial University, St John, NFLD, Canada

ABSTRACT: The emerging fungal pathogen Cryptococcus neoformans is a major cause of pneumonia, meningitis, and disseminated disease in the immune compromised. We have previously used a clinically relevant model of infection to investigate the genetic determinants of susceptibility to cryptococcal pneumonia in susceptible C57BL/6J and resistant CBA/J inbred mice. A genome-wide linkage analysis performed on 210 male and 203 female [CBA/J x C57BL/6J] F2 progeny identified three genetic loci (Cnes1-Cnes3) that are associated with susceptibility to cryptococcal pneumonia. Cnes1 $(\mathrm{P}=0.0110)$ is located on chromosome 3 while the Cnes2 $(\mathrm{P}<0.0001)$ and Cnes3 $(\mathrm{P}<0.010)$ loci flank the major histocompatibility (H-2) complex on chromosome 17 , a region that is commonly associated with susceptibility or resistance to both infectious and autoimmune diseases. A role for the $\mathrm{H}-2$ complex in host susceptibility to C. neoformans could not be excluded since segregation of the $\mathrm{H}-2 \mathrm{k} / \mathrm{k}$ $(\mathrm{CBA} / \mathrm{J})$ and $\mathrm{H}-2 \mathrm{~b} / \mathrm{b}(\mathrm{C} 57 \mathrm{BL} / 6 \mathrm{~J})$ haplotypes was observed in this study. To formally evaluate the influence of the $\mathrm{H}-2$ locus on susceptibility, $\mathrm{C} 57 \mathrm{BL} / 6 \mathrm{~J}$ mice congenic for the $\mathrm{H}-2 \mathrm{k} / \mathrm{k}$ haplotype (B6.H2k) and control C57BL/6J (H-2b/b) were intratracheally infected with $10^{4} \mathrm{CFU}$ of encapsulated C. neoformans 24067 and the pulmonary fungal burden was measured at day 35 . The B6.H2k congenic mice were equally susceptible to the control C57BL/6J (H-2b/b) mice (B6.H2k: mean log CFU $=6.24 \pm 0.46$ vs. $\mathrm{C} 57 \mathrm{BL} / 6 \mathrm{~J}$ : mean $\log \mathrm{CFU}=6.27 \pm 0.23 ; \mathrm{P}=0.96$ ) demonstrating that in our model the major histocompatibility complex region does not significantly influence host defense against cryptococcal pneumonia and is distinct from Cnes2 and Cnes3.

\section{1}

\section{LA MIGRATION DE L'ÉOSINOPHILE INDUITE PAR LES ÉOTAXINES}

V Provost, A Langlois, M Rola-Pleszczynski, M Laviolette Centre de recherche de I'Hôpital Laval, Institut universitaire de cardiologie et de pneumologie, Québec et I' Unité d'immunologie, Département de pédiatrie, Faculté de Médecine, Université de Sherbrooke, Sherbrooke, QC, Canada

L'asthme est caractérisé par une inflammation bronchique causée notamment par l'infiltration d'éosinophiles. Un des puissants chimioattractant de l'éosinophile est l'éotaxine-1. Récemment, deux autres éotaxines ont été identifiés, soit l'éotaxine-2 et l'éotaxine-3. Leur effet sur la migration Des éosinophiles demeure encore peu étudié et aucune étude n'a comparé leur efficacité. À l'aide d'essais de migration au travers une mince couche de matrice extracellulaire simulant une membrane basale, nous avons étudié l'efficacité des trois éotaxines à induire la migration d'éosinophiles. Les éosinophiles ont été isolés à partir du sang de sujets sains et asthmatiques et incubées avec différentes concentrations d'éotaxine-1, -2 et -3 pendant 9,12 et 18 heures. Après 18 heures d'incubation, les migrations optimales d'éosinophiles de sujets asthmatiques sont de $52 \%$ pour l'éotaxine-1 $(-8 \mathrm{M}), 43 \%$ pour l'éotaxine-2 $(-8 \mathrm{M})$ et $72 \%$ pour l'éotaxine-3 $(-7 \mathrm{M})$. La migration induite par l'éotaxine-3 est significativement plus puissante comparativement à celle induite par l'éotaxine-1 $(\mathrm{p}=0.01)$ et par l'éotaxine-2 ( $\mathrm{p}=0.001)$. De plus, la migration des éosinophiles induite par l'éotaxine-3 est plus rapide que celle induite par les éotaxines 1 et 2 $(\mathrm{p}=0.01)$. La migration d'éosinophiles induite par l'éotaxine-1 et -3 chez les sujets asthmatiques est plus forte comparativement à celle induite chez les sujets sains $(\mathrm{p}=0.03)$. L'éotaxine- 3 est un chimioattractant plus puissant et plus rapide que les éotaxines 1 et 2 pour l'éosinophile. De plus, son efficacité est plus importante chez les sujets asthmatiques comparativement aux sujets sains. Cette étude suggère que l'éotaxine-3 pourrait largement contribuer à l'infiltration d'éosinophiles dans la muqueuse bronchique des sujets asthmatiques.

\section{2 \\ ÉTUDIER LES BACTÉRIES INFECTANT LES PERSONNES FIBRO-KYSTIQUES AUTREMENT GRÂCE À UNE AMIBE}

SJ Charette, G Filion, L Vial, E Déziel, RC Levesque

Centre de recherche de I'Hôpital Laval, Institut Armand Frappier et Université Laval

La fibrose kystique (FK) est une maladie génétique fréquente au Québec. Les personnes souffrant de FK ont une production excessive de mucus dans leurs poumons qui favorise l'implantation de pathogènes opportunistes comme Pseudomonas aeruginosa, Burkholderia cenocepacia et B. multivorans. Une fois dans le poumon, ces bactéries ont la capacité de modifier leur physiologie pour y assurer leur survie et leur prolifération. Elles peuvent ainsi devenir résistantes à des traitements aux antibiotiques et à l'action du système immunitaire. Une meilleure compréhension du comportement de ces bactéries est indispensable pour développer de nouvelles approches thérapeutiques plus efficaces et appropriées au contexte de l'infection pulmonaire chronique vécue par les personnes FK. Cela implique une étude de la relation hôte-pathogène qui est souvent compromise par des raisons éthiques, économiques et pratiques. Mon laboratoire s'intéresse donc à l'étude de la virulence des bactéries infectant les personnes fibro-kystiques en utilisant un hôte de remplacement. Cet hôte est l'amibe, Dictyostelium discoideum et il présente de nombreux avantages pour l'étude du comportement des bactéries pathogènes. Nos premiers résultats suggèrent que la virulence de souches bactériennes responsables d'infections respiratoires comme P. aeruginosa LESB58 et de diverses souches de Burkholderia peuvent être analysées avec $D$. discoideum. Ces résultats ouvrent la porte à l'identification des facteurs de virulence de ces bactéries ; une étape essentielle à l'élaboration de nouveaux traitements permettant d'augmenter la qualité de vie et l'espérance de vie des personnes souffrant de FK.

\section{3} CORRÉLATION ENTRE LE QUESTIONNAIRE GÉNÉRIQUE
SF-36 ET LE QUESTIONNAIRE RESPIRATOIRE DE
ST-GEORGE CHEZ LES PATIENTS MPOC SUITE À UN
PROGRAMME ÉDUCATIF D'AUTOGESTION

H Favreau, KL Lavoie, K Rabhi, M Labrecque

Hôpital du Sacré-Coeur de Montréal, Université du Québec à

Montréal

INTRODUCTION : L'évaluation de la qualité de vie reliée à la santé (QdVS) chez les patients (p) MPOC fournit une information unique en son genre et complète les mesures physiologiques traditionnelles. Il a été démontré que l'état psychologique était un meilleur prédicteur du niveau de QdVS chez les p MPOC que les résultats de spirométrie. De plus, il semble que les mesures physiologiques détectent peu les effets des programmes d'intervention chez les $\mathrm{p}$ MPOC. Un programme éducatif d'autogestion (PEA) peut augmenter la QdVS chez les p MPOC. Ainsi, mesurer la QdVS peut être utile dans l'évaluation de l'efficacité d'un tel programme. Cette étude évalue l'évolution de la QdVS à 3 mois et à 1 an chez les $\mathrm{p}$ MPOC suite à un PEA.

MÉTHODE : L'essai clinique ouvert était formé de p atteints de MPOC documentée et stable, le groupe (gr.) intervention ( $\mathrm{Tx}$ ) comptait $57 \mathrm{p}$ et le gr. contrôle 45. Un PEA de 4 sem. (3h/sem.) par gr. de 8-10 p MPOC a été administré. Le programme vise à informer les $\mathrm{p}$ sur les différents aspects reliés à la MPOC et de leur enseigner les comportements à prendre pour l'autogestion de leurs exacerbations. Les p ont été évalués à 3 mois et à 1 an post-tx. La QdVS a été mesurée par deux questionnaires : un évalue la qualité de vie globale (SF-36) et l'autre évalue la qualité de vie reliée à la MPOC (SGRQ). 
RÉSULTATS: ANOVAS à mesures répétées pour le SGRQ: 1) Interactions significatives du $T x \times$ temps au score total $(p<.001)$, au domaine «Impact » $(\mathrm{p}<.001)$ et au domaine « symptômes » $(\mathrm{p}=.028) .2)$ Au domaine «Impact » avec le temps, amélioration significative du score moyen pour le gr. Tx $(-8.7 ; \mathrm{p}<.001)$ et dégradation du gr. contrôle $(+4.8 ; \mathrm{p}=.05)$. Résultats du SF-36:1) Interactions significatives du Tx x temps au score total de la dimension «mentale» $(\mathrm{p}<.001)$ et de la dimension physique $(\mathrm{p}=.029)$. 2) À la dimension « mentale » avec le temps, amélioration significative du score moyen pour le gr.Tx $(+4.5 ; \mathrm{p}=.019)$ et dégradation significative du gr.contrôle $(-5.1 ; \mathrm{p}=.013) 3)$ À la dimension « physique » aucun changement significatif avec le temps autant pour le gr. Tx que le gr. contrôle.

CONCLUSION: Un PEA améliore de façon substantielle la qualité de vie des p MPOC, et cela principalement au niveau psychologique. Cela a été détecté par les questionnaires auto-administrés de qualité de vie, autant pour la santé globale (SF-36) que spécifique à la MPOC (SGRQ).

\section{4}

\section{INCREASED EXPRESSION OF TH17-ASSOCIATED} CYTOKINES IN ATOPIC DERMATITIS

O Roshdy ${ }^{1}$, D Prefontaine ${ }^{1}$, F Chouiali ${ }^{1}$, A Vazquez-Tello ${ }^{1}$, M Boguniewicz ${ }^{2}$, M Howell ${ }^{2}, \mathrm{R} \mathrm{He}^{3}$, RS Geha ${ }^{3}$, DY Leung², Q Hamid ${ }^{1}$

${ }^{1}$ Meakins-Christie laboratories, McGill University, Montreal, Canada; ${ }^{2}$ National Jewish Health, Denver, Colorado; ${ }^{3}$ Children's Hospital, Harvard Medical School, Boston, MA

RATIONALE: Atopic dermatitis (AD) is a common inflammatory skin disease, closely related to asthma, both being parts of the systemic disorder; atopy. Autoimmunity has been suggested to play a role in the pathogenesis of AD. The recently described TH17 cells are reported to be involved in the pathogenesis of some autoimmune diseases. The objective of this study is to examine the expression of the TH17-associated cytokines in AD patients and explore the presence of this $\mathrm{T}$ cell subset particularly in chronic lesions.

METHODS: AD patients (acute and chronic) were recruited together with a comparable group of normal subjects $(n=10 /$ group). Biopsy specimens were taken from each. The expression of IL-17A and IL-17F was studied using immunocytochemistry. Using laser capture microdissection (LCM), we isolated inflammatory cells, then investigated the expression of TH17-associated cytokines mRNA by quantitative real time PCR. Serum IL-17A levels were measured by ELISA in $20 \mathrm{AD}$ patients and 13 healthy controls.

RESULTS: We detected significantly higher numbers of IL-17A and IL-17F immunoreactive cells in AD cases compared (especially in chronic) to controls. We successfully isolated mononuclear inflammatory cells from skin of chronic AD lesions by LCM and have demonstrated the expression of IL-17 mRNA. Serum IL-17A levels were detected in 6 of 20 AD but in non of 13 healthy controls ( $\mathrm{p}<0.05$; Chi square).

CONCLUSION: Our data suggest that TH17-associated cytokines are highly expressed in chronic AD lesions and that IL-17A is present in the circulation of some AD patients. Further investigations will aim to examine the functional significance and the clinical implications of TH17associated cytokines in the pathogenesis of AD.

\section{5}

\section{MONITOREP OU MONITORAGE INTRA THORACIQUE OPTIQUE DE LA REPARATION PULMONAIRE IN VIVO... : VOYAGE DANS LES ABYSSES DU POUMON}

Clément Fournier ${ }^{1}$, Frédéric Chagnon ${ }^{1}$, Daniel M Payet ${ }^{1}$, Paul Charrette ${ }^{1}$, Steven Thomas ${ }^{2}$, Peter Delaney ${ }^{2}$, Olivier Lesur ${ }^{1}$ U de Sherbrooke Qc Canada et Optiscan Pty Ltd Victoria, Australia ${ }^{1}$ Université de Sherbrooke Qc Canada; et ${ }^{2}$ Optiscan Pty Ltd Victoria, Australia

PRÉMISSES : Les outils d'évaluation d'une amélioration clinique du SDRA sont peu sensibles et peu spécifiques. Une biopsie pulmonaire ouverte serait idéale mais comporte des risques inacceptables pour des patients déjà malades. La surveillance en « temps-réel » de la réparation pulmonaire pourrait être accessible par technique de micro-imagerie, et ainsi permettre de changer la conduite du clinicien sur des critères objectifs sensibles et spécifiques.

OBJECTIFS/MÉTHODES GÉNÉRAUX : Développer la microimagerie laser de fluorescence confocale in vivo (Five 1, Optiscan) du poumon à l'aide d'un contraste systémique ou local par l'usage de marqueur(s) équipé(s) d'un agent fluorophore (FITC), et permettant de visionner par application directe sur la plèvre viscérale pulmonaire les processus de réparation.

Des rats normaux et des rats instillés avec de la Bléomycine intrapulmonaire sont comparés. Nous utilisons les produits suivants : Acridine Orange, Acriflavine, Dextran-FITC, Flivo, Annexin, PKH2.

RÉSULTATS : Grâce à cette technique, certains paramètres peuvent être observés. La démonstration iconographique permet d'envisager l'établissement de scores d'inflammation et de réparation, faisant miroiter des algorithmes interventionnels susceptibles d'aider les réanimateurs dans leurs décisions thérapeutiques vis à vis des patients atteints de SDRA.

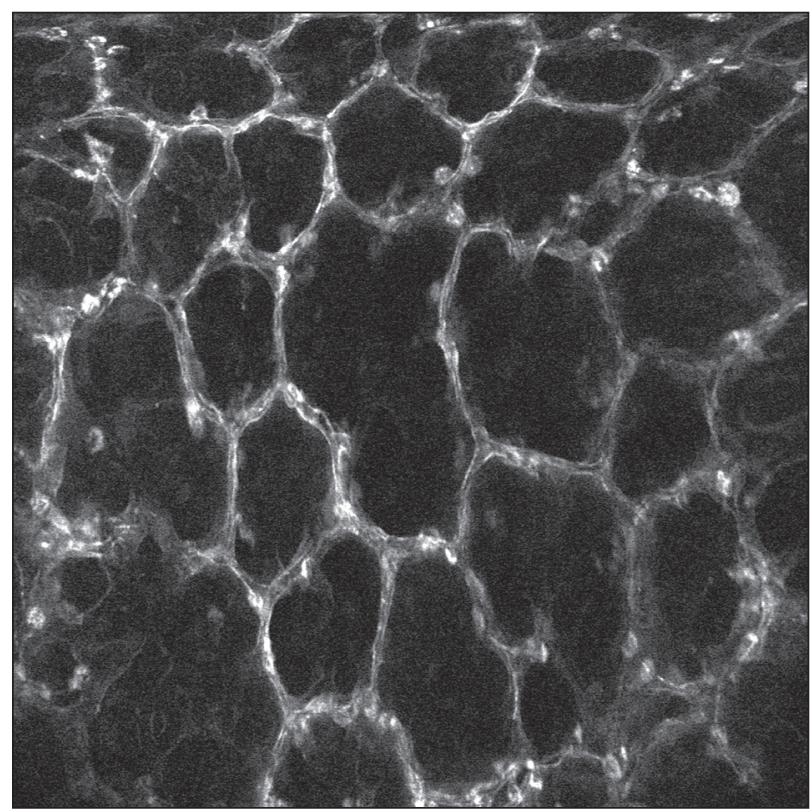

CONCLUSION : une technique d'imagerie intra-vitale pulmonaire prometteuse est en développement afin de déterminer ultimement des paramètres de monitorage et de pronostic des agressions pulmonaires aigues de type SDRA et de les appliquer au chevet des patients de réanimation.

Support : RSR-FRSQ, CRC, Fac de Génie UDS

\section{6}

FIABILITÉ D'UN QUESTIONNAIRE POUR MESURER LES CONNAISSANCES DES PATIENTS ATTEINTS DE MALADIES PULMONAIRES OBSTRUCTIVES CHRONIQUES (MPOC)

M Labrecque MD MSC, K Rabhi PHD

Centre De Recherche De L'hôpital Sacré-Coeur De Montréal INTRODUCTION: Les connaissances des patients atteints de MPOC peuvent contribuer à l'autogestion de leur maladie et améliorer ainsi leur qualité de vie. La mesure des connaissances des sujets atteints de MPOC a été testée dans une population de 102 patients âgés de 40 à 75 ans par le biais d'un questionnaire développé spécialement dans le cadre d'un essai clinique prospectif destiné à évaluer l'effet d'un programme d'éducation sur la qualité de vie.

MÉTHODE: Le programme d'autogestion développé à l'Hôpital SacréCoeur est basé sur le programme des maladies pulmonaires obstructives chroniques élaboré par Boehringer-Ingelheim, ('Living Well With COPD'). Il est constitué de 12 modules répartis en quatre sessions, étalé sur une période de un mois. L'enseignement porte sur l'anatomie, les mécanismes physiologiques de la respiration, le cycle respiratoire et la conservation de l'énergie et sur les signes et les symptômes de la MPOC. Le questionnaire 
des connaissances développé dans ce projet comporte quatre sections de cinq questions chacune et correspond à une session spécifique du programme d'intervention. Les connaissances des patients ont été évaluées avant et après le programme et mise en relation avec les dimensions physiques et psychologiques de la qualité de vie liée à la santé. Une analyse factorielle de correspondance multiple (HOMALS procédure) a permis d'apprécier la cohérence interne du questionnaire et l'analyse test-retest a mesuré la reproductibilité lors de deux administrations successives à un mois d'intervalle chez 45 patients du groupe de référence.

RÉSULTATS: L'analyse longitudinale (pré-test, post-test) montre un gain de connaissance significatif dans le groupe intervention $(\mathrm{P}=.001)$ après le programme éducatif d'auto-gestion. L'analyse factorielle de correspondance multiple montre une bonne cohérence interne du questionnaire résumé par un coefficient alpha de Cronbach de 0.76 et l'analyse test-retest montre une très bonne reproductibilité démontrée par un coefficient de corrélation de .84 dans le groupe de référence.Toutes les analyses ont été réalisées à l'aide du logiciel statistique SPSS.

CONCLUSION: La fiabilité de l'instrument (sois la cohérence interne et la reproductibilité) a été étudié et démontre que le questionnaire des connaissances sur la MPOC développé dans le cadre de cette étude est un outil valable.

\section{7}

\section{ALTÉRATION DE LA VARIABILITÉ CARDIAQUE CHEZ LES PATIENTS ATTEINTS DE MALADIE PULMONAIRE OBSTRUCTIVE CHRONIQUE}

\section{Bédard, K Marquis, S Provencher, P Poirier}

Institut de cardiologie et de pneumologie, Hôpital Laval, Québec, Québec

INTRODUCTION : Une variabilité cardiaque altérée est un facteur de mauvais pronostic démontré dans de multiples pathologies et chez la population en santé.

OBJECTIF : Étudier la variabilité cardiaque des patients atteints de maladie pulmonaire obstructive chronique (MPOC) et évaluer l'impact de la prise de médication anti-cholinergique et $B$-agoniste.

MÉTHODE : Quarante-deux patients cliniquement stables atteints de MPOC et dix-neuf sujets témoins appariés pour l'âge, le sexe et l'histoire tabagique ont effectués un enregistrement de type Holter de vingt-quatre heures. L'analyse de la variabilité cardiaque a été faite selon les analyses temporelle et spectrale reconnues.

RÉSULTATS : Les patients atteints de MPOC présentent une variabilité cardiaque globale (ratio LF/HF) diminuée comparés aux sujets témoins de jour, de nuit et pour l'ensemble des vingt-quatre heures (ratio LF/HF jour: 2,96 \pm 2,07 vs $4,48 \pm 2,35, \mathrm{P}<0,01$; nuit: $3,06 \pm 3,02$ vs $4,87 \pm 3,12$, $\mathrm{P}<0,01$; vingtquatre heures: $2,81 \pm 2,03$ vs $4,53 \pm 2,40, P<0,01$ ). Il n'y a pas de différence significative entre les deux groupes pour les données de l'analyse temporelle (NN, SDNN, SDANN, rMSSD et pNN50) ou les basses et hautes fréquences. Il existe une corrélation positive significative entre le volume expiratoire maximal sur une seconde (VEMS) en litres et le ratio $\mathrm{LF} / \mathrm{HF}(\mathrm{r}=0,346, \mathrm{P}=0,025)$. En analyse multivariée, le ratio $\mathrm{LF} / \mathrm{HF}$ est indépendamment relié à l'âge $(\mathrm{r}=-0,082, \mathrm{P}=0,046)$ et la relation avec le VEMS est à la limite d'être significative $(r=1,174, P=0,054)$. Il n'y a aucune différence de variabilité cardiaque entre les patients prenant ou non une médication anti-cholinergique ou $\beta$-agoniste.

\section{8}

\section{PROJET D'ÉDUCATION THÉRAPEUTIQUE DU PATIENT ASTHMATIQUE EN MÉDECINE DE VILLE : RÉSULTATS ET PERSPECTIVES D'AVENIR}

\section{F Martin-Dupont, J Boisvert, M Sapene, T Dubon} Réseau d'éducation asthme et allergie Aquitaine INTRODUCTION : Issu de l'association «Asthme et Allergie 33 » et de l'«Ecole de l'Asthme » existant depuis 1994, ce projet a été financé par le Fonds d'Aide à la Qualité des Soins de Ville de décembre2003 à juin 2005.

MÉTHODES : Après avoir formé le médecin à l'éducation thérapeutique et plus particulièrement au diagnostic éducatif, le médecin envoie les éléments du dossier partagé (diagnostic éducatif, objectifs du patient) au centre qui convie le patient à une session d'éducation thérapeutique. L'engagement initial du patient est proposé par le médecin traitant, qui fixe avec le patient les objectifs à atteindre (contrat d'éducation). Le médecin traitant est informé de l'évolution du patient dans son éducation, ce qui renforce la relation médecin patient et maintient la motivation de ces deux acteurs.

RÉSULTATS : Cette recherche a fait l'objet d'une publication dans Actualité et dossier en santé publique (AdSP) revue trimestrielle du Haut Conseil de la santé publique. «L'éducation thérapeutique du patient asthmatique suivi en médecine de ville vaut-elle le coût ? " n 59 juin 2007. Période de l'évaluation : novembre 2003-septembre 2005 (Réunions de formation médecins : 11; Médecins formés : 50; Médecins incluant : 32; Patients inclus : 153; Nombre de sessions : > 50; Nombre d'événements éducatifs : 450) A un an: Dans le domaine pédagogique, les connaissances sont améliorées et intégrées (Reconnaître les signes annonciateurs de la crise, connaissance du rôle des médicaments, des techniques d'inhalation, adopter un plan d'action en cas de crise,...) Dans le domaine psychosocial, la perception de la maladie a évolué (meilleur niveau de santé perçu) Dans le domaine clinique, l'observance s'améliore et les exacerbations de la maladie sont limitées Il a été reconnu un impact économique positif.

DISCUSSION : Les résultats montrent que les patients peuvent s'engager dans la démarche éducative par l'intermédiaire du médecin traitant. Depuis juin 2006, le réseau d'Education Asthme Allergie Aquitaine (grâce à un financement de Dotation Régionale de Développement des Réseaux), recrute les patients par l'intermédiaire du médecin traitant. Le bilan provisoire 2008 est très encourageant: 130 médecins généralistes ou spécialistes adhérant au réseau; 200 nouveaux patients (600 patients depuis 2003); 40 sessions d'éducation thérapeutique, 200 patients; 300 événements éducatifs (Diagnostic éducatif, séances d'éducation collective, visite de suivi). De nouvelles activités ont été créées telles que: Activité physique adaptée (assurée par des enseignants en activité physique adapté); Conseil médical en environnement intérieur; Atelier asthme et allergies alimentaires etc... La collaboration avec les médecins traitants est possible, facilitée par une bonne communication auprès de ceux-ci, sur la base de dire que l'Education thérapeutique renforce la relation médecin traitant-patient et la rend plus agréable et efficace.

\section{9}

\section{LE 2-ARACHIDONOYLGLYCÉROL (2-AG) INDUIT LA SYNTHÈSE DE LEUCOTRIÈNES (LT) PAR LES NEUTROPHILES HUMAINS (PMN)}

F Chouinard $^{1,3}$, JS Lefebvre ${ }^{2,3}$, M Laviolette $^{1,3}$, N Flamand ${ }^{1,3}$ ${ }^{1}$ Centre de recherche de I'Hôpital Laval, ${ }^{2}$ Centre de recherche en rhumatologie et immunologie du CHUL et ${ }^{3}$ Faculté de médecine, Université Laval, Québec, Canada

Les endocannabinoïdes tels que le 2-AG et l'anandamide (AEA) diminuent l'inflammation en activant les récepteurs des cannabinoïdes (CB). Cependant, des études suggèrent qu'ils augmenteraient aussi l'inflammation en recrutant et activant les leucocytes. Les endocannabinoïdes sont vite hydrolysés en acide arachidonique (AA), le précurseur d'éicosanoïdes proinflammatoires comme les LT. Nous postulons que 1) l'AA issu de l'hydrolyse des endocannabinoïdes est métabolisé en LT ; et 2) ces LT sont impliqués dans les effets pro-inflammatoires attribués aux endocannabinoïdes.

MÉTHODES : Des PMN humains ont été incubés avec du 2-AG ou de l'AEA et les LT produits analysés par HPLC ou LC-MS/MS. La mobilisation de $\mathrm{Ca}^{2+}$ a été mesurée par fluorescence chez des PMN chargés en Fura-2. La chimiotaxie a été étudiée avec des chambres de Boyden.

RÉSULTATS : Le 2-AG (mais pas l'AEA) a induit une synthèse importante de LT par les PMN, comparable à celle obtenue avec de l'AA. Cet effet du 2-AG a été bloqué par le MAFP, qui inhibe son hydrolyse. L'utilisation de 2-AG deutéré confirma que les LT néoformés dérivent de l'AA contenu dans le 2-AG. Les agonistes et antagonistes du récepteur CB2 n'ont pas modifié la synthèse des LT induite par le 2 AG. La mobilisation de $\mathrm{Ca} 2+$ et la chimiotaxie induites par le 2-AG ont été bloquées par le MAFP ou un antagoniste du BLT1, suggérant que l'activation des PMN par le 2-AG est la conséquence de son hydrolyse et d'une néosynthèse de 
LTB4. Cette étude dévoile un lien fonctionnel entre l'hydrolyse du 2-AG, la synthèse des LT et l'activation des PMN et supporte l'utilisation d'inhibiteur de l'hydrolyse des endocannabinoïdes comme thérapie antiinflammatoire.

\section{0}

\section{EFFECTS OF PROTEOGLYCANS ON HUMAN AIRWAY SMOOTH MUSCLE CELL ATTACHMENT}

ML D'Antoni BSc ${ }^{1}$, P Ferraro MD², JG Martin MD ${ }^{1}$, MS Ludwig $\mathrm{MD}^{1}$

${ }^{1}$ Meakins Christie Labs, McGill University, Montreal, Canada; and ${ }^{2}$ University of Montreal Hospital Centre, Montreal, Canada

Growth on decorin (dcn) matrix results in decreased human airway smooth muscle cell (HASMC) number, by decreasing proliferation and increasing apoptosis (D'Antoni, Am J Physiol Lung 2008). Appropriate extracellular matrix (ECM)-cell interaction is essential in conveying survival signals to the cell. We questioned whether the increased apoptosis was related to abnormal ECM-cell attachment. HASMC, from lung transplant recipients, were seeded on decorin $(\mathrm{dcn})$, biglycan (bgn), collagen type I (col I) $(1,3$ and $10 \mu \mathrm{g} / \mathrm{ml})$. After $48 \mathrm{~h}$ growth arrest (time 0$)$, cells were stimulated with platelet-derived growth factor (PDGF). Actin organization and focal adhesion formation were assessed by staining cells for filamentous (F) and globular (G) actin, and vinculin, respectively, at 0, 24 and $48 \mathrm{~h}$ post $P D G F$. Cells, fixed with $4 \%$ paraformaldehyde and permeabilized with Triton X-100 (0.1\%), were stained for F- and G-actin with fluorescently-labelled phalloidin and DNase I, respectively. Vinculin was stained using indirect immunofluorescence. Visualization was done with confocal microscopy. F-actin was prominent in cells seeded on col I (1, 3 and $10 \mu \mathrm{g} / \mathrm{ml})$. F-actin in cells seeded on dcn $(10 \mu \mathrm{g} / \mathrm{ml})$ was less evident; cells appeared round and filaments were either faint or absent. Cells seeded on bgn $(10 \mu \mathrm{g} / \mathrm{ml})$ were intermediate. Vinculin clustering at the cell surface was clearly visible in cells seeded on col I $(1,3$ and $10 \mu \mathrm{g} / \mathrm{ml})$. Focal adhesion formation was affected by bgn and den $(10 \mu \mathrm{g} / \mathrm{ml})$ however, as vinculin was more diffusely distributed within the cytoplasm. HASMC seeded on decorin may undergo increased apoptosis due to the lack of appropriate cell attachment to the matrix.

\section{1}

\section{CORRECTION OF F508DEL-CFTR TRAFFICKING BY THE BIOAVAILABLE COMPOUND JMCG811}

R Robert ${ }^{1}$, GW Carlile ${ }^{3}$, J Liao ${ }^{1}$, N Liu ${ }^{1}$, B Kus ${ }^{4}$, D Rotin ${ }^{4}$, DY Thomas ${ }^{3}$, JW Hanrahan ${ }^{1,2}$

Depts. of ${ }^{1}$ Physiology, ${ }^{2}$ McGill University Health Centre Research Institute and ${ }^{3}$ Biochemistry, McGill Univ., Montréal, Québec and ${ }^{4}$ Dept. of Biochemistry, Univ. Toronto, Ontario

BACKGROUND: Cystic Fibrosis (CF) is the result of mutations in the cystic fibrosis transmembrane conductance regulator (CFTR) gene. The most common mutation F508del mutation impairs CFTR maturation and trafficking to the plasma membrane. One promising approach to new CF therapeutics is to identify drugs that have been developed for other indications which correct the CFTR trafficking defect, thereby exploiting their known safety and bioavailability in humans to reduce the time required for clinical development.

PURPOSE: To find new correctors of F508del-CFTR processing defect by screening approved, marketed and off-patent drugs with known safety and bioavailability in humans.

RESULTS: Amongst the confirmed hits was an anthranilic acid derivative with analgesic properties which we have named JMCG811. It partially corrected F508del-CFTR processing and increased its surface expression. Treating BHK cells with $10 \mu \mathrm{M}$ JMCG811 for $24 \mathrm{~h}$ significantly increased the amount of complex glycosylated F508del-CFTR on Western-blots. Partial correction of F508del-CFTR-mediated anion transport was confirmed in three different cell types that express heterologous F508del-CFTR and using two assays of halide permeability. Incubating polarized CFBE41omonolayers and intestines isolated from F508del mice with $10 \mu \mathrm{M}$ JMGC811 increased the short-circuit current response to forskolin+genistein. In vivo treatment with JMGC811 partially restored the total salivary secretion by $15 \%$ of that observed for non-CF mice. The results suggest that JMCG811 may be useful for the treatment of CF, although further medicinal chemistry may be required to minimize sideeffects.

Supported by CFF and CIHR (BREATHE Program)

\section{2}

\section{SENSIBILITÉ ACCRUE DU PARENCHYME PULMONAIRE EMPHYSÉMATEUX À L'APOPTOSE INDUITE PAR TRAIL COMME UNE CONSÉQUENCE D'EXPOSITION À UN STRESS OXYDANT: IMPACTS SUR LA PATHOGENÈSE DE L'EMPHYSĖME ET SUR DE NOUVELLES THÉRAPIES ANTI- TUMORALES}

MC Morissette, J Parent, J Milot

Centre de Recherche de I'Hôpital Laval, Institut Universitaire de Cardiologie et de Pneumologie de I'Université Laval, Québec,

Canada

Le poumon emphysémateux présente une apoptose alvéolaire accrue. Cependant, les mécanismes impliqués ne sont pas clairs. Récemment, il a été suggéré que les cellules alvéolaires de sujets emphysémateux pourraient être sensibles à l'apoptose induite par TRAIL dû à la présence d'un stress oxydant. Ce phénomène s'avèrerait également très important puisque de nouvelles thérapies anti-tumorales basées sur l'administration de TRAIL atteignent les essais cliniques.

MÉTHODES: Des portions de poumons fraîchement réséqués provenant de sujets normaux (SN) et emphysémateux (SE) ont été exposées au rTRAIL pendant $18 \mathrm{~h}$ avant d'en mesurer l'activité de la caspase-3 (actC3). De plus, les cellules alvéolaires A549 ont été exposées au rTRAIL, au $\mathrm{H}_{2} \mathrm{O}_{2}$ et/ou à un extrait de fumée de cigarette (CSE) avant la mesure de l'actC3 et le marquage à l'annexin $\mathrm{V}(\mathrm{AV})$.

RÉSULTATS: Les tissus pulmonaires provenant de SN exposés ex vivo au rTRAIL ont une actC3 diminuée $(-13 \% \pm 6 \%[\mathrm{n}=4])$ alors que les tissus de SE ont une actC3 augmentée $(+26 \% \pm 8 \%[n=3])$ par rapport aux tissus non-exposés. Les cellules A549 exposées au rTRAIL, au $\mathrm{H}_{2} \mathrm{O}_{2}$ et au CSE ont respectivement montré une augmentation de $55 \%, 60 \%$ et $10 \%$ de l'actC3 et $8 \%, 4 \%$ et $8 \%$ de cellules $\mathrm{AV}+$, alors que les cellules exposées au rTRAIL et au $\mathrm{H}_{2} \mathrm{O}_{2}$ ou au CSE ont montré une augmentation de $450 \%$ et $310 \%$ de l'actC3 et $38 \%$ et $25 \%$ de cellules $\mathrm{AV}+$.

CONCLUSION: Ces résultats démontrent que la sensibilité à l'apoptose induite par TRAIL est augmentée chez les SE et potentiellement attribuable au stress oxydant. De plus, ces résultats suggèrent que les nouvelles thérapies anti-tumorales basées sur TRAIL pourraient causer d'importants dommages chez les emphysémateux.

\section{3}

\section{OPTIMIZING MEDICAL PRACTICE IN COPD: THE RECAP PROJECT}

MF Sedeno BEng, MM, M Lebel RN, J Bourbeau MD

Montréal Chest Institute, McGill University, Montréal, Québec, Canada

STUDY OBJECTIVES: RECAP (Rehabilitation, Education for COPD, and Added-value to the medical Practice) aimed to optimize COPD medical practice at the McGill University Health Centre (MUHC).

METHODS: We report on a program to improve COPD medical practice introduced in three MUHC hospitals. The program included a priori evaluation of medical practice via chart review. Patients having hospital admissions or emergency room visits due to COPD were selected from a stratified sample size representative of each center (2003-2006). For each patient the care provided for the chronic disease (at discharge) was evaluated and compared to COPD guidelines (CTS, 2003). A model of knowledge translation was used to improve medical practice by implementing specific interventions at each stage of the change process: awareness, agreement, adoption and adherence.

RESULTS: A chart review of 221 patients (mean 74 years, FEV $_{1} 31 \%$ predicted) showed a number of care gaps: spirometry (only $34 \%$ in 2 of 3 centers), only $21 \%$ patients were on optimal treatment, reference to pulmonary rehabilitation rarely done (34\% referred in 2 of 3 sites) and 
follow-up in the community (36\%). A program of continuous education was set-up, providing more than 280 hours of training (awareness). Discussion of the care gaps led to the involvement of over 130 health professionals, including respirologists, internists, nurses and managers (agreement and adoption). As a result, new quality practice indicators have been adopted and integrated to the MUHC accreditation; thus to assure the sustainability of the improvement process beyond the RECAP project (adherence).

CONCLUSIONS: The RECAP project has obtained organizational commitment to implement a quality process, including practice indicators to enhance COPD care at the MUHC.

\section{4 \\ RÉGULATION DE LA SÉCRÉTION DE LA MMP-9 PAR LES ÉOSINOPHILES SANGUINS}

M-C Roy Bsc, A Langlois MSc, M Laviolette MD

Unité de recherche en pneumologie, Centre de recherche de I

Hôpital Laval, Université Laval, Québec, Qc

INTRODUCTION: Pour passer du sang vers la muqueuse bronchique, l'éosinophile, activé par un chimioattractant, sécrète des protéases, dont le système plasminogène/plasmine et la métalloprotéinase (MMP)-9. L'acide 5-oxo-6,8,11,14-éicosatetraénoique (5-oxo-ETE) active la sécrétion de la MMP-9 via la voie de signalisation « extracellular signal-regulated kinase » (ERK)-1/2, ce qui permet la migration des éosinophiles. Nos résultats suggèrent que l'effet de ERK-1/2 sur la migration diminue en absence de plasminogène.

HYPOTHÈSE: Nous postulons que le système plasminogène/plasmine permet la production de la MMP-9 en phosphorylant ERK-1/2.

MÉTHODES: Des éosinophiles sanguins purifiés furent stimulés avec une dose croissante d'urokinase et de plasmine. Dans quelques expériences, les éosinophiles furent pré-incubés avec ou sans inhibiteur spécifique de ERK (PD 98059) pendant 30 min à $37^{\circ} \mathrm{C}$ avant d'être stimulés. La sécrétion de la MMP-9 dans le surnageant a été mesurée par western blot.

RÉSULTATS ET CONCLUSION: L'urokinase et la plasmine activent la sécrétion de la MMP-9. L'inhibition de la phosphorylation d'ERK-1/2 diminue cette production de MMP-9 chez les éosinophiles sanguins. Ces résultats démontrent que la phosphorylation de ERK est impliqué dans la génération de MMP-9 induite par la plasmine et par l'urokinase. Les mécanismes d'action de l'urokinase et de la plasmine restent à être mieux définis.

\section{5}

WILD-TYPE CFTR ENHANCES THE BARRIER FUNCTION OF AIRWAY EPITHELIAL CELL MONOLAYERS

P LeSimple ${ }^{1}$, J Liao'1, J Hanrahan ${ }^{1,2}$

${ }^{1}$ McGill University Department of Physiology, Montreal, QC, Canada; ${ }^{2}$ McGill University Health Centre Research Institute, Montreal, QC, Canada

Cystic Fibrosis (CF) is caused by mutations in the chloride channel CFTR, the most common of which is $\Delta \mathrm{F} 508$, which leads to a defect in CFTR trafficking to the plasma membrane of epithelia. CFTR plays a major role in salt transport and cell signaling but its possible involvement in maintaining epithelial integrity has not been studied. We examined the influence of CFTR on barrier function using polarized human CF (CFBE41o-) and non-CF (CALU-3) airway epithelial cell monolayers cultured at the air-liquid interface as a model. CFTR was localized by immunofluorescence staining, and epithelial tightness was assayed by measuring transepithelial resistance (TER) and radiolabelled mannitol backflux. Transient expression of GFP-CFTR in CF monolayers increased TER whereas overexpressing GFP- $\Delta$ F508 had no effect. Similar results were obtained using stable cell lines that CFTR vs $\Delta F 508$, i.e. monolayers expressing heterologous wild-type CFTR (CFBE-CFTR) had higher TER and lower mannitol backflux compared to those stably expressing $\Delta$ F508 CFTR. Rescue of $\Delta$ F508 trafficking at $29^{\circ} \mathrm{C}$ increased TER to levels similar to CFBE-WT monolayers, reversibly and reproducibly through four cycles between 37 $29^{\circ} \mathrm{C}$. Pharmacological inhibition of CFTR did not inhibit the increase in TER. Our results demonstrate that CFTR apical localization is important for epithelial barrier function. We suggest that binding of CFTR to subapical protein complexes is necessary for the organization of the cytoskeletton and/or the junctional complexes, and this may contribute to the transport defects observed in CF.

Support CCFF and CIHR (BREATHE program).

\section{6}

\section{EFFETS SYSTÉMIQUES ET MUSCULAIRES DE L'HYPOXIE CHRONIQUE DANS UN MODĖLE DE SOURIS.}

M-A Caron, M-E Thériault, M-E Paré, F Maltais, $R$ Debigaré

Centre de recherche, Hôpital Laval, Institut Universitaire de Cardiologie et de Pneumologie de I'Université Laval. Québec, Qc, Canada

La maladie pulmonaire obstructive chronique est fréquemment accompagnée d'une diminution de la masse musculaire périphérique. Bien que les causes exactes menant à cette manifestation clinique soient méconnues, l'implication de l'hypoxémie est probable. Nos données accumulées dans un modèle de myotubes musculaires indiquent que l'hypoxie peut promouvoir l'atrophie musculaire en diminuant la synthèse des protéines tout en augmentant leur dégradation. Dans cette étude, nous avons développé un modèle animal dont l'objectif est d'étudier les effets systémiques et locaux d'une exposition hypoxique. Des souris C57BL/6 ont été exposées 14 jours à $21 \% \mathrm{O}_{2}(\mathrm{Con}, \mathrm{n}=6), 1 \% \mathrm{O}_{2}(\mathrm{Hyp}, \mathrm{n}=6)$ ou $21 \% \mathrm{O}_{2}$ avec un apport alimentaire comparable à celui du groupe Hyp $(\mathrm{PF}, \mathrm{n}=6)$. Une perte de poids total rapide et constante a été observée dans le groupe Hyp $(\mathrm{p}<0.05)$. Au niveau systémique, le VEGF était augmenté dans le groupe Hyp $(\mathrm{p}<0.05)$ alors que l'IGF-1 était diminué dans le groupe PF $(\mathrm{p}<0.05)$. Aucun changement au niveau de la taille des fibres ou de l'accumulation d'un fragment d'actine, un marqueur de dégradation des protéines contractiles, n'a été observé dans le gastrocnemius (GAS). Finalement, aucune différence significative au niveau de la phosphorylation d'Akt ou de GSK3\&\#946; n'a été mesurée.

CONCLUSION: Une perte de poids a été observée dans le groupe Hyp malgré un niveau similaire d'IGF-1 entre les groupes Con et Hyp, suggérant une incapacité de l'IGF-1 à préserver la masse corporelle en hypoxie. Les résultats obtenus avec le GAS ne supportent pas la présence d'atrophie dans ce muscle. Dans l'ensemble, nos résultats offrent des pistes pour perfectionner le développement de ce modèle.

\section{7}

\section{BÂTIR LES ÉVIDENCES SCIENTIFIQUES SUR L'AUTOGESTION EN MPOC : LA CONTRIBUTION DU QUÉBEC}

J Bourbeau MD MSc FRCPC, M Sedeno MM et le RSR du FRSQ Unité d'épidémiologie et de recherche clinique de l'Institut thoracique de Montréal, Centre universitaire de santé McGill INTRODUCTION : Une approche de soins chroniques incluant l'éducation avec autogestion de la maladie gagne en popularité dans la pratique auprès des patients atteints de maladie pulmonaire obstructive chronique (MPOC).

OBJECTIFS : Présenter les données probantes disponibles à ce jour qui découlent de recherches faites au Québec sur l'autogestion de la MPOC et permettent de démontrer l'efficacité et l'efficience d'un programme d'éducation avec autogestion « Mieux Vivre avec une MPOC ».

ÉTUDES ET RÉSULTATS : En 2003, un essai clinique randomisé multicentre québécois a permis d'établir, en toute première, qu'un programme d'éducation sur l'autogestion de la MPOC avec suivi par un gestionnaire de cas améliorait la qualité de vie des patients et diminuait de plus de $40 \%$ les visites à l'urgence et les admissions à l'hôpital. En 2005, une autre étude québécoise confirmait les bénéfices à long terme. Une évaluation économique démontrait le coût-efficacité d'une telle approche, une situation certes, enviable. Une étude qualitative complémentaire, faite par des infirmières québécoises, établissait que les stratégies d'autogestion de la MPOC les plus aidantes sont les principes de conservation d'énergie, la respiration à lèvres pincées, l'utilisation d'un plan d'action et la pratique d'exercices physiques. Plus récemment en 2006, il était démontré, encore une fois au Québec, que l'observance à un plan d'action lors d'exacerbations 
de la MPOC était un facteur déterminant de la diminution des admissions à l'hôpital.

CONCLUSIONS : Le Québec a contribué à rehausser les standards de recherche clinique en gestion de soins, à devenir une référence dans le domaine et à bâtir les évidences de l'efficacité d'une approche de soins avec autogestion en MPOC.

\section{8}

\section{VARIATIONS SAISONNIÈRES DU RÉFLEXE DE TOUX CHEZ LES ATHLÈTES S'ENTRAîNANT EN AIR FROID}

J Turmel, V Bougault, P Poirier, LP Boulet

Unité de recherche en pneumologie, Centre de recherche de

I'Hôpital Laval, Institut universitaire de cardiologie et de

pneumologie, Université Laval, Québec, (Québec)

INTRODUCTION : La toux est un symptôme respiratoire très fréquent chez les athlètes d'hiver. L'irritation chronique des bronches, due à l'hyperventilation d'air froid, contribuerait à l'augmentation de la réponse sensitive des récepteurs tussigènes. Objectif : Déterminer si l'exposition saisonnière au froid, chez les athlètes d'hiver, induit une réduction transitoire du seuil réflexe de la toux.

MÉTHODES : Cinquante-huit athlètes d'hiver et 33 sujets sédentaires appariés ont complété un questionnaire sur les symptômes respiratoires et réalisé un test d'inhalation à la capsaicine $(\mathrm{C} 5)$, à chaque saison. Une expectoration induite, un test cutané d'allergie, un test de provocation à la métacholine (CP20) et un test d'hyperventilation eucapnique (HVE) ont aussi été réalisé.

RÉSULTATS : Les athlètes rapportent plus de toux $1 \mathrm{~h}$ après l'exercice en hiver comparativement à la saison estivale $(\mathrm{p}=0,04)$. La prévalence de toux $1 \mathrm{~h}$ suivant l'exercice est plus importante chez les athlètes que chez les contrôles $(\mathrm{p}=0,02)$. La prévalence d'hypersensibilité du réflexe de toux $\left(\mathrm{C}_{5} \leq 32 \mu \mathrm{M}\right)$ est similaire chez les athlètes et les contrôles pour toutes les saisons. Le seuil du réflexe de la toux (C5) est inchangé à travers les saisons chez les athlètes et les contrôles et aucune différence n'est observée entre les 2 groupes. Chez les athlètes, la chute du VEMS au test d'HVE est corrélée au seuil du réflexe de toux, cette relation étant plus importante à l'hiver $(\mathrm{r}=0.61, \mathrm{p}=0.03)$. Aucune corrélation significative n'a été observée entre la réactivité bronchique à la métacholine, le pourcentage d'éosinophiles et de neutrophiles dans l'expectoration induite, l'atopie et le seuil du réflexe de toux.

CONCLUSION : Il n'existe pas de variation saisonnière du réflexe de toux chez les athlètes ni chez les contrôles. La toux ne semble pas être associée à la réactivité bronchique à la métacholine, aux allergies ou à l'inflammation bronchique. Par contre, elle semble associée à la réponse à l'HVE.

\section{9}

\section{EFFET DE L'EXPOSITION PRECOCE A LA FUMEE DE CIGARETTE SUR LA COORDINATION DES DEGLUTITIONS NON NUTRITIVES AVEC LA RESPIRATION CHEZ L'AGNEAU NOUVEAU-NÉ}

C Duvareille, M St-Hilaire, N Samson, J-P Praud

Unité de recherche respiratoire néonatale. Université de Sherbrooke, Qc, Canada

Les déglutitions non-nutritives (DNN) sont essentielles pour la clairance des reflux gastropharyngés, fréquents chez le nouveau-né. De plus, une parfaite coordination DNN-respiration est cruciale pour la prévention des aspirations et des apnées. Impliquée dans le syndrome de mort subite du nourrisson, l'exposition à la fumée de cigarette $(\mathrm{EFC})$ perturbe les déglutitions chez l'adulte (Dua K, Gut 1998 ; 2002). Le but de ce projet est d'étudier les effets d'une EFC postnatale précoce sur la fréquence des DNN et sur la coordination DNN-respiration chez l'agneau nouveau-né.

Six agneaux nouveau-nés ont été exposés à 20 cigarettes par jour (C20) comparés à 5 agneaux exposés à l'air $(\mathrm{C} 0)$ durant 15 jours. Au jour 12, les agneaux ont été instrumentés pour l'enregistrement des stades de conscience, respiration, DNN et électrocardiogramme. Une polysomnographie par radiotélémetrie a été effectué au jour 15.

Le rapport cotinine / créatinine urinaire est augmenté avec l'EFC (CO: $8 \pm 10$ ng.mg-1; C20: $1531 \pm 331$ ng.mg-1). Aucun effet de l'EFC n'a été observé sur la fréquence des DNN (C0: $36 \pm 5$ min-1; C20: $27 \pm 9$ min-1) et sur la coordination DNN-respiration en sommeil calme (CO: iDNN / eDNN : $15 \pm 3 / 6 \pm 3$ h-1, ieDNN / eiDNN : $10 \pm 5 / 4 \pm 2$ h-1; C20 : iDNN / eDNN : $9 \pm 4$ / $7 \pm 4$ h-1, ieDNN / eiDNN : $8 \pm 5$ / $4 \pm 2$ h-1). Des résultats identiques sont observés en sommeil agité et à l'éveil.

L'exposition postnatale précoce à la fumée de cigarette n'a pas d'effet sur la fréquence des déglutitions non-nutritives et sur leur coordination avec la respiration. Les effets d'une exposition prénatale et/ou postnatale prolongée nécessitent des études supplémentaires.

Support IRSC

\section{0}

SENSITIZATION-SITE DEPENDENT PRODUCTION OF TH17 CELLS AND IL-17

E Nakada, M Kinyanjui, J Shan, E Fixman

Meakins-Christie Laboratories, McGill University

BACKGROUND: How Th17 cells and IL-17 regulate allergic airways disease in murine models is poorly understood. Evidence suggests that the site of allergen sensitization may affect production of Th17 cells and IL-17. Two routes of allergen sensitization commonly used are intraperitoneal (i.p.) and intranasal (i.n.). We have quantified Th17 cell induction and IL-17 production in mice exposed to ovalbumin (OVA) i.n. or sensitized i.p. with OVA in alum.

METHODS: Mice were exposed i.n. to OVA $(25 \mu \mathrm{g}) 3$ times per week for 4 weeks and sacrificed $48 \mathrm{~h}$ after the last OVA administration. Alternatively, mice were sensitized i.p. with OVA $(100 \mu \mathrm{g})$ in alum on days 1 and 8 and sacrificed on day 15. Splenocytes from each group were cultured with OVA and harvested at various time points up to 6 days. CD4 ${ }^{+}$Th17 cells expressing CCR6 were quantified by FACS analysis. IL-17 mRNA and protein levels were quantified by RT-PCR and ELISA.

RESULTS: Small amounts of IL-17 mRNA were present in freshly harvested splenocytes from each group and increased upon culture with OVA. The percentage of CCR6 $6^{+}$Th17 cells was lower in freshly harvested splenocytes from i.p. sensitized mice. CCR6 ${ }^{+}$Th17 cells increased in each group upon culture with OVA, though levels from i.p. sensitized mice were lower. The kinetics of IL-17 protein production were similar in each group, although larger amounts of IL-17 were produced by splenocytes from i.n. exposed mice.

CONCLUSION: Th17 cells were present in freshly harvested splenocyte populations from mice following i.p. sensitization or i.n. exposure to OVA. Upon culture with OVA, the percentage of Th17 cells and IL-17 production increased. Th17 cell induction appears to be more efficient in mice exposed to OVA via the i.n. route.

\section{1}

IMPACT DE LA FATIGUE DU QUADRICEPS SUR LA CHARGE VENTILATOIRE À L'EXERCICE DANS LA MALADIE PULMONAIRE OBTSRUCTIVE CHRONIQUE (MPOC)

P Gagnon, D Saey, I Vivodtzev, L Laviolette, S Provencher, J Milot, F Maltais

Centre de recherche clinique en pneumologie, Hôpital Laval, Québec, Quebec

L'intolérance à l'effort dans la MPOC résulte d'une interaction complexe entre la composante centrale (ventilatoire) et périphérique (musculaire).

BUT: Évaluer l'influence de la fatigue du quadriceps sur la tolérance à l'effort et la réponse ventilatoire dans la MPOC.

MÉTHODES: Quinze sujets MPOC et neuf témoins appariés pour l'âge ont réalisé deux épreuves d'endurance sur ergocycle à $80 \%$ de la charge maximale prédéterminée : l'une dans un état frais et l'autre dans un état fatigué, l'ordre étant randomisé. La fatigue musculaire fût induite par électrostimulation des quadriceps et objectivée par mesures de force maximale volontaire (FMV) et de stimulation magnétique ( $\mathrm{TwQ}$ ). Le temps d'endurance et la réponse ventilatoire à iso-temps étaient comparés dans chaque groupe entre l'état fatigué et non-fatigué.

RÉSULTATS: Suite au protocole d'électrostimulation, la chute de TwQ était équivalente entre MPOC (moy \pm SEM; $30 \pm 3 \%)$ et témoins $(35 \pm 5 \%)$ alors que la chute de FMV était plus marquée chez les témoins $(25 \pm 2 \%$ 
vs. $17 \pm 2 \%, \mathrm{p}<0.05)$. Le temps d'endurance était significativement réduit en condition fatiguée, autant pour les MPOC $(356 \pm 69 \mathrm{sec}$ vs. $294 \pm 45 \mathrm{sec}$, $\mathrm{p}<0.05)$ que pour les témoins $(450 \pm 74 \mathrm{sec}$ vs. $340 \pm 45 \mathrm{sec}, \mathrm{p}<0.05)$. Les témoins ont démontrés une élévation significative de la ventilation et du score maximal de dyspnée en condition fatiguée, alors que chez les MPOC aucune augmentation de la ventilation, ni de la dyspnée n'a été observée. CONCLUSION: La fatigue du quadriceps réduit la tolérance à l'effort chez les MPOC et les sujets sains. Une ventilation et une dyspnée plus marquée ont été observées à l'état fatigué chez les témoins sans que ce ne soit observé chez les MPOC.

\section{2}

EFFICACITÉ ET TOLÉRANCE DU LAVAGE BRONCHOALVÉOLAIRE (LBA) EN VENTILATION LIQUIDIENNE TOTALE (VLT) DANS UN MODÈLE EXPÉRIMENTAL NÉONATAL OVIN DE SYNDROME D'ASPIRATION MÉCONIALE (SAM): RÉSULTATS D'UNE ÉTUDE PILOTE

O Avoine, B Beaudry, D Bossé, J-P Praud, P Micheau, H Walti Département de pédiatrie, Physiologie et Biophysique (Faculté de médecine et des sciences de la santé) et département de génie mécanique (Faculté de génie) - Université de Sherbrooke, Quebec INTRODUCTION: Le SAM, pathologie pulmonaire par inhalation périnatale de liquide amniotique teinté de méconium, est responsable d'une importante morbidité cardiorespiratoire et d'une mortalité entre 5 et $10 \%$. Des essais ont démontrés l'efficacité de la ventilation liquidienne partielle pour réaliser un LBA lors du SAM. La VLT a été moins étudiée. OBJECTIFS: 1) Développer un modèle expérimental néonatal ovin de SAM. 2) Tester l'efficacité et la tolérance du LBA en VLT.

MÉTHODE: Sept agneaux nouveau-nés $(<4 \mathrm{j}, 2,5-5 \mathrm{~kg})$ étudiés. Après intubation ils étaient placés en ventilation mécanique conventionnelle (VMC) $\left(\mathrm{FiO}_{2}=1.0\right)$, anesthésiés et curarisés. Après la pose de cathéters pour la surveillance des gaz du sang et de l'hémodynamique par thermodilution, un SAM était induit par instillation trachéale $(2 \times 1 \mathrm{ml} / \mathrm{kg})$ d'une solution de méconium humain homogénéisée à $25 \%$. Les critères d'un SAM atteint $\left(\mathrm{PaO}_{2}<100\right.$ torr $\left./ \mathrm{FiO}_{2}=1.0\right)$ les agneaux étaient placés en VLT (INOLIVENT 4) pour tester l'efficacité et optimiser les paramètres du LBA en VLT. Les animaux étaient retournés en VMC pour $1 \mathrm{~h}$ et euthanasiés.

RESULTATS: Valeurs moyennes (SD) après induction du SAM : $\mathrm{PaO}_{2}$, $\mathrm{PaCO}_{2}$ (torr) et pH de 55.0 (6.6) ; 51.9 (7.6) et 7.25 (0.035). En VLT optimisée à une ventilation minute de $160 \mathrm{~mL} / \mathrm{min}: \mathrm{PaO}_{2}, \mathrm{PaCO}_{2}$ et $\mathrm{pH}$ moyen de 235.7 (45.1) ; 45.8 (4.9) et 7.27 (0.032). Nous n'avons noté aucun effet hémodynamique indésirable.

CONCLUSION: Nos résultats démontrent que le LBA en VLT est efficace et bien toléré dans ce modèle de SAM. Un essai randomisé comparant l'efficacité et la tolérance entre LBA en VLT et en VMC, avec une solution de surfactant dilué, est en cours.

\section{3}

\section{INHIBITION DE L'ACTIVATION ANTIGÉNIQUE DES MASTOCYTES PAR LES MACROPHAGES ALVÉOLAIRES : COLLABORATION DES CELLULES ÉPITHÉLIALES BRONCHIQUES}

\section{J-F Lauzon-Joset, A Dubé, E Bissonnette}

Centre de recherche de I'Hôpital Laval, Institut universitaire de cardiologie et de pneumologie, Université Laval, Quebec

OBJECTIF : Les macrophages alvéolaires (MA) jouent un rôle important dans l'homéostasie pulmonaire. Nous avons démontré le rôle protecteur in vivo des MA contre la réaction asthmatique immédiate et l'hyperréactivité bronchique suite à une exposition allergénique. Étant donné le rôle important des mastocytes $(\mathrm{MC})$ dans la réaction allergique, nous avons étudié la capacité des MA à moduler l'activation de ces cellules.

MÉTHODES : Une lignée murine de MC (RBL-2H3) et de MA (NR8383) ont été mises en co-culture avec ou sans contact cellulaire. Les mastocytes ont été stimulés avec l'antigène et le relâchement de prostaglandines D2 (PGD2), de béta-hexosaminidase (b-hex) et d'interleukine-4
(IL-4) a été mesuré à 15 min, 30 min et 6 h respectivement. Pour déterminer l'implication des cellules épithéliales bronchiques (CE), celles-ci ont été ajoutées à la co-culture de MA et de MC.

RÉSULTATS : La stimulation des MC avec l'antigène a augmenté la sécrétion de b-hex, de PGD2 et d'IL-4. En présence de MA, le relâchement de b-hex et de PGD2 n'a pas été modifié, seule la sécrétion d'IL-4 a été inhibée de façon significative. De plus, le contact cellulaire a augmenté cet effet. L'addition de CE ou de MA n'a pas affecté la dégranulation des $\mathrm{MC}$, mais la co-culture de $\mathrm{CE}$ et de $\mathrm{MA}$ avec les $\mathrm{MC}$ a inhibé la libération de b-hex.

CONCLUSION : Les MA inhibent les fonctions pro-inflammatoires à long terme des mastocytes et ce, sans contact cellulaire. De plus, les MA en présence de $\mathrm{CE}$ inhibent la dégranulation des $\mathrm{MC}$. Nos résultats suggèrent qu'il existe une communication intercellulaire complexe afin de limiter l'activation des MC.

\section{4}

\section{CD40-MEDIATED CELL DEATH INDUCTION THROUGH CATHEPSIN B}

M Jundi, A Nadiri, W Mourad

Centre hospitalier de l'Université Montréal, Hôpital St-Luc, Department of Microbiology and immunology, Université de Montréal, Montreal, Quebec

BACKGROUND: CD40 is a type I phosphorylated glycoprotein which plays a major role in the immune response by contributing to antibody production, cell proliferation, and cell death. It is well known that the blockage of CD40-CD154 interaction prevent pulmonary inflammation and fibrosis. Inflammed airway epithelial cells show an increased CD40 expression.

PURPOSE: Our aim is to study the difference between CD40 monomers and dimers in the induction of programmed cell death, which is proposed as a target in various autoimmune disease therapies.

METHODS / RESULTS: In order to do that, we used different human cell lines endogenously expressing CD40 and those exogenously expressing wild type CD40 or mutant CD40 unable to form homodimers. We also used chemical inhibitors in order to characterize the signalling pathways involved in cell death induction by CD40. Our results showed a correlation between CD40 cell surface expression and the level of CD40mediated cell death. Furthermore, we observed that CD40 homodimer formation was not required for cell death induction; however, the monomeric form of CD40 increased the level of cell death. In addition, CD40induced cell death was reduced when we blocked the interaction between CD40 and TRAF6. CD40-mediated apoptosis was significantly inhibited when cathepsin B inhibitor was used. In summary, our results demonstrate that a high level of CD40 expression is required in CD40-mediated cell death. This process is dependent on cathepsin B and TRAF6. Ultimately, we believe that this study will help in the elaboration and the enhancement of therapies targeting depletion of hyperresponsive and inlfammed cells in chronic respiratory disease.

\section{5}

LES CYSTÉNYLS LEUCOTRIÈNES AUGMENTENT LA PRODUCTION DE COLLAGĖNE CHEZ LES FIBROBLASTES DE SUJETS ASTHMATIQUES VIA LE RÉCEPTEUR DES CYSTÉNYLS LEUCOTRIÈNES 2 (CYSLT-R2)

R Eap, E Jacques, S Plante, J Chakir

Centre de recherche, Hôpital Laval, Institut Universitaire de Cardiologie et de Pneumologie de I'Université Laval, Québec, Québec

INTRODUCTION : Le remodelage bronchique dans l'asthme est caractérisé par une fibrose subépithéliale tel le dépôt de collagène de type 1 chez les fibroblastes bronchiques. Les cystényls leucotriènes (CysLTs) sont des médiateurs lipidiques possédant de larges propriétés pro-inflammatoires. Leurs effets sur le remodelage bronchique ne sont jusqu'ici que peu explorés. OBJECTIF : Évaluer les effets des CysLTs sur la synthèse du procollagène $1(\mathrm{a} 1)$ de fibroblastes bronchiques isolés de sujets sains et de sujets asthmatiques légers. 
MÉTHODES : L'expression des récepteurs des cystényls leucotriènes (CysLT-R) a été déterminée par qPCR et western blot. L'expression de l'ARNm procollagène $1(\mathrm{a} 1)$ a été déterminée par qPCR après stimulation avec différentes concentrations de LTD4 avec ou sans antagonistes des CysLT-R : antagoniste sélectif du CysLT-R1, le montélukast (MK); et un antagoniste non-sélectif du CysLT-R1 et CysLT-R2, le BAY -u9773 (BAY).

RÉSULTATS : L'expression de l'ARNm et de la protéine du CysLT-R1 chez les sujets asthmatiques sont surexprimées comparée aux sujets sains. LTD4 (100nM) est capable d'augmenter l'expression du procollagène 1(a1). MK (10-8M) inhibe seulement chez les sujets sains l'expression du procollagène $1(\mathrm{a} 1)$. BAY $(10-8 \mathrm{M})$ inhibe chez les 2 catégories de sujets l'expression du procollagène 1 (a1).

CONCLUSION : Nous avons démontré que le LTD4 induit une expression du procollagène 1(a1) par les 2 CysLT-R chez les fibroblastes de sujets sains. Cependant, chez les sujets asthmatiques, cette induction semble passer uniquement par le CysLT-R2.

Supporté par le Programme d'études proposées par des chercheurs canadiens de Merck Frosst

\section{6}

\section{WORKERS' EXPOSURE TO AIRBORNE PATHOGENS IN SWINE CONFINEMENT BUILDINGS OF EASTERN CANADA ACCORDING TO THE PRODUCTION SYSTEM}

Valérie Létourneau ${ }^{1}$, Benjamin Nehmée ${ }^{2}$, Anne Mériaux ${ }^{3}$, Ann Letellier ${ }^{4}$, Daniel Massé ${ }^{5}$, Caroline Duchaine ${ }^{1,3}$

${ }^{1}$ Université Laval, Québec, QC, Canada; ${ }^{2} \mathrm{CHUL}$, Québec, QC, Canada, ${ }^{3}$ Hôpital Laval, Québec, QC, Canada; ${ }^{4}$ Université de Montréal, Saint-Hyacinthe, QC, Canada, ${ }^{5}$ Agriculture and Agri-Food Canada, Lennoxville, QC, Canada

RATIONALE: The trend in Eastern Canadian swine production is toward totally enclosed, well-insulated buildings with controlled ventilation, either fan-powered or naturally ventilated. As the production increased, new buildings using different production systems (conventional, sawdust litter, source separation of urine and faeces) emerged. Aerosols in these buildings are known to be constituted of feces-originating zoonotic pathogens (e.g. Clostridium perfringens). Aerosols and the nasopharyngeal flora of hog producers were analyzed to investigate workers exposure to aerosolized zoonotic pathogens inside swine confinement buildings using different production systems.

METHODS: Aerosolized mesophilic bacteria and pathogens were collected with Andersen 6 stages and AGI-30 in 18 swine confinement buildings using different production systems. Mesophilic bacteria, Campylobacter, C. perfringens, Enterococcus, Escherichia coli and Yersinia enterocolitica were quantified by culture and PCR on extracted DNA from AGI-30 solutions. Nasopharynx of 34 workers and non-exposed controls was sampled with a calcium alginate swab. Total DNA from swabs was extracted and ribosomal ARN 16S genes from C. perfringens, Enterococcus, E. coli and Y. enterocolitica were detected by real-time PCR.

RESULTS: Buildings using sawdust were more contaminated by airborne culturable mesophilic bacteria and culturable Enterococcus than buildings without $(\mathrm{p}<0.01)$. Airborne culturable Enterococcus concentrations were correlated to culturable mesophilic bacteria $(p<0.01)$. C. perfringens and E. coli were respectively recovered up to 103 and $101 \mathrm{CFU} / \mathrm{m}^{3}$ by culture. Culturable Y. enterocolitica were occasionally found in few aerosols. Total zoonotic pathogens concentrations $\left(16 \mathrm{~s} \mathrm{rDNA} / \mathrm{m}^{3}\right)$ were not different according to the used production system. Thirteen out of 34 nasopharyngeal floras of hog producers were contaminated with species of Enterococcus, 10 with E. coli and 1 with Y. enterocolitica while none of the controls were positive for the studied zoonotic pathogens.

CONCLUSION: The highest culturable concentrations of aerosolized bacteria and Enterococcus found in buildings with sawdust may be explained by the lower temperature and the presence of sawdust, a nutriments-rich organic matter, inside these facilities. Consequently, colonization of workers by aerosolized bacteria and Enterococcus may be facilitated in buildings with sawdust. With no consideration to the used production system, hog producers from modern confined buildings are exposed to harmful aerosolized zoonotic pathogens which might colonize their nasopharynx.
Financial support: Agriculture and Agri-Food Canada, NSERC, INSPQ, PHARE training program (VL and BN) and FRSQ (CD)

\section{7}

\section{REGULATION OF ALVEOLAR ENAC CHANNEL EXPRESSION BY K ${ }^{+}$CHANNELS}

O Bardou, K Roy-Camille, A Privé, A Dagenais, Y Berthiaume,

E Brochiero.

Département de Médecine, Université de Montréal, CR-CHUM

BACKGROUND: $\mathrm{Na}^{+}$reabsorption through $\mathrm{ENaC}$ channels has been shown crucial for alveolar clearance. In addition, we previously demonstrated that $\mathrm{K}_{\mathrm{ATP}}$ and $\mathrm{KvLQT1} \mathrm{K}^{+}$channel activities control $\mathrm{Na}^{+}$and $\mathrm{Cl}^{-}$transport as well as fluid transport across alveolar epithelia in primary culture. Interestingly, we also observed that $\mathrm{K}_{\mathrm{ATP}}$ and KvLQT1 modulators regulated $\mathrm{ENaC}$ and CFTR channel $\mathrm{mRNA}$ and protein expressions.

AIM: To further study the regulatory mechanisms of ENaC expression, we decided to evaluate the impact of $\mathrm{K}^{+}$channel modulation on $\mathrm{ENaC}$ promoter activity.

METHODS AND RESULTS: We first identified by PCR and Westernblotting, three $\mathrm{K}^{+}$channels, $\mathrm{K}_{\mathrm{ATP}}$, KvLQT1 and KCa3.1, expressed in the alveolar cell line A549. We then confirmed that ENaC mRNA expression was upregulated by KATP activator pinacidil (32\%) and downregulated by $\mathrm{K}_{\mathrm{ATP}}$, KvLQT1 and KCa3.1 inhibitors, glibenclamide (32\%), clofilium (29\%) and Tram34 (24\%), respectively. $\mathrm{K}^{+}$channel inhibitors, used in combination, elicited an additive inhibitory effect. To study the impact of $\mathrm{K}^{+}$channel activity on $\mathrm{ENaC}$ promoter, A549 cells were transfected with $\alpha$-ENaC-Luc construct. We found a dose response increase in $\mathrm{ENaC}$ promoter activity following pinacidil treatment (53\% increase with $100 \mu \mathrm{M}$ pinacidil). Conversely, $\mathrm{K}_{\mathrm{ATP}}$ inhibition with $50 \mu \mathrm{M}$ glibenclamide significantly reduced (27\%) ENaC promoter activity.

CONCLUSIONS AND PERSPECTIVES: We are evaluating, in parallel, the regulation CFTR promoter activity by these $\mathrm{K}^{+}$channel modulators. We think that the regulation of ENaC and CFTR channels by $\mathrm{K}^{+}$ channel modulators could be beneficial for the resolution of lung pathologies characterised by ion and fluid transport dysfunction.

\section{8}

\section{LA GRANULOMATOSE SARCOIDE NÉCROSANTE : SUIVI D'UN CAS}

T Vandemoortele, $\mathrm{P}$ Mayer

Hôtel-Dieu de Montréal, Centre Hospitalier de l'Université de Montréal

Une patiente de 31 ans s'est présentée avec une anomalie à la radiographie simple du poumon, 6 ans après avoir été traitée pour un lymphome. Découverte fortuitement, cette anomalie correspondait à 2 lésions, dont une médiastinale et l'autre parenchymateuse, intimement accolées l'une à l'autre à la tomodensitométrie axiale et qui démontraient un hypermétabolisme intense à la tomodensitométrie par émission de positron. Comme une récidive du lymphome était suspectée, et que les tentatives de biopsie par voie trans-thoracique, puis par médiastinoscopie s'étaient avérées nondiagnostiques, une résection en coin de la lésion pulmonaire fut effectuée. Celle-ci a démontré la présence d'un processus granulomateux nécrosant avec une infiltration inflammatoire de la paroi des vaisseaux, évoquant la possibilité d'une granulomatose sarcoïde nécrosante. Une revue de la littérature concernant cette pathologie est rapportée.

\section{9}

UN RESPIRATEUR POLYVALENT AVEC OPTION NÉONATALE EST IL AUSSI PERFORMANT QU'UN RESPIRATEUR DÉDIÉ AU NOUVEAU-NÉ? ÉVALUATION SUR BANC D'ESSAI

M Fontana ${ }^{1}$, S Morneau ${ }^{1}$, A Payot ${ }^{1}$, M Cyr ${ }^{1}$, F Lellouche ${ }^{2}$, P Jouvet ${ }^{1}$ ${ }^{1} \mathrm{CHU}$ Ste-Justine- Montréal, ${ }^{2}$ Hôpital Laval-Québec

OBJECTIF : Comparer les performances néonatales de respirateurs polyvalents à celles d'un respirateur exclusivement néonatal.

MÉTHODES : Les respirateurs polyvalents Servo-I (Maquet), Evita XL (Dräger Medical) et le respirateur néonatal Babylog 8000 (Dräger Medical) ont été connectés à un poumon test et testés en simulant différentes situations cliniques. 
RÉSULTATS : La qualité du système de déclenchement était comparable pour les trois respirateurs testés avec un délai de déclenchement de 45-60 ms et une dépression maximale de $0.08-0.14 \mathrm{~cm} \mathrm{H}_{2} \mathrm{O}$ pour un appel inspiratoire de $-2 \mathrm{cmH}_{2} \mathrm{O}$. La performance à pressuriser $(\mathrm{PTP}=$ Produit Temps x Pression) à $150 \mathrm{~ms}$ du Servo-I était plus haute $\left(0.74 \mathrm{cmH}_{2} \mathrm{O}\right)$ que celles de Evita XL $\left(0.41 \mathrm{cmH}_{2} \mathrm{O}\right)$ et Babylog $\left(0.25 \mathrm{cmH}_{2} \mathrm{O}\right)$. Les trois respirateurs surcompensent une augmentation de résistance de 200 $\mathrm{cmH}_{2} \mathrm{O} / \mathrm{l} / \mathrm{s}$ avec un différence de max $10 \%$ du volume délivré. La précision de du volume, de la pression inspiratoire (PIP) et de la PEEP prescrits étaient de 95 à $99 \%$ pour l'Evita XL, 92 à $96 \%$ pour le Servo-I et 80 à $96 \%$ pour le Babylog. Une variation de débit expiratoire de $1.5 \mathrm{~L} / \mathrm{min}$ amène à une minime variation de la PEEP avec les trois respirateurs (de 0.1 à 0.3 $\mathrm{cmH}_{2} \mathrm{O}$ ). La PIP varie avec le même débit varie au max. de $1 \mathrm{~cm} \mathrm{H}_{2} \mathrm{O}$ (Servo-I). Une variation brutale de la compliance peut amener à des variations importantes du volume délivré (augmentation de 10 à $31 \mathrm{ml}$ pour l' Evita XL et de 10 à $17 \mathrm{ml}$ pour le Servo-I).

CONCLUSIONS : Le Servo-I et l'Evita XL ont montré des performances comparables et parfois meilleures sur banc d'essai en comparaison avec un respirateur dédié au nouveau-né.

\section{0}

NEURALLY ADJUSTED VENTILATORY ASSIST MODE (NAVA) IN INFANTS

A Bordessoule, P Jouvet, V Payen, S Morneau, J Beck service SI pediatrique CHU Sainte Justine Montreal

BACKGROUND: A new ventilation mode that detects diaphragm electrical activity was developed to improve synchronization and to deliver a proportional respiratory assistance to patient effort,: Neurally Adjusted Ventilatory Assist mode (NAVA). We performed an evaluation of NAVA in infants during the weaning phase.

OBJECTIVES: To evaluate the feasibility, efficacy and tolerance of NAVA mode in infants.

METHODS: Infants hospitalized in the pediatric intensive care unit of Sainte Justine Hospital where daily screened from January to October 2008. They were included in the study if they fulfilled the following criteria: i) $<1$ year of age, ii) mechanically ventilated in assist mode, iii) pressure plateau (above PEEP) $<22 \mathrm{cmH}_{2} \mathrm{O}$ and iv) PEEP $\leq 6 \mathrm{cmH}_{2} \mathrm{O}$. After inclusion, a gastric tube with electric diaphragmatic activity (EAdi) electrodes was inserted and infants were ventilated with Servoi ventilator. Infants were ventilated according to the following sequence: $30 \mathrm{~min}$ with initial settings, 6hrs in NAVA with PEEP and NAVA level titrations, $30 \mathrm{~min}$ in assist control mode (PAC) and 30min in pressure support mode (PS). Patient vital signs were continuously monitored; ventilator parameters and EAdi were continuously recorded. Efficacy was evaluated on patient-ventilator synchrony (trigger delay). Tolerance was evaluated on respiratory pattern (respiratory rate, tidal volume, $\mathrm{SpO}_{2}$ and $\mathrm{ETCO}_{2}$ maintained in normal range or not during NAVA session).

RESULTS: Eight patients were included $(5.7 \pm 1.6$ months old and $4.1 \pm$ $1.8 \mathrm{~kg}$ ). EAdi was correctly detected during NAVA session in all patient with naso-gastric tube $(n=8)$. In 1 patient with oro-gastric tube detection fluctuated and required a switch to naso-gastric tube. After titration, PEEP and NAVA level were $4.7 \pm 1.4 \mathrm{cmH}_{2} \mathrm{O}$ and $2.3 \pm 2.6 \mu V_{\text {olt }} / \mathrm{cmH}_{2} \mathrm{O}$ respectively. At the end of the 6 hours in NAVA mode, $\mathrm{SpO}_{2}, \mathrm{FiO}_{2}$ and end tidal $\mathrm{PCO}_{2}$ were $98 \pm 2 \%, 30 \pm 0 \%$ and $40 \pm 9 \mathrm{mmHg}$, respectively. Synchronization to diaphragm contraction seemed to be better during NAVA when compared to AC and PS. Tolerance was good during NAVA session. Inspiratory pressure delivered was proportional to EAdi level even during sigh.

CONCLUSIONS: NAVA is feasible in infants when a naso-gastric tube is used to monitor electric diaphragm activity. This mode was well tolerated and seemed to improve patient-ventilator synchrony when compared to conventional modes.

\section{1}

\section{LE REMODELAGE ET L'HYPERREACTIVITÉ DES VOIES AÉRIENNES (HR) SONT DISSOCIÉS DANS UN MODÈLE D'ASTHME ALLERGIQUE CHEZ LE RAT BROWN NORWAY}

S. Siddiqui, T Jo, K Shalaby, M Bernabeu, JG Martin Laboratoires de Meakins-Christie, Université de McGill, Montréal, Canada

INTRODUCTION : Chez le rat sensibilisé, la provocation allergénique (PA) induit un remodelage des voies aériennes (VA). L'objectif de ce travail était d'étudier la relation entre les fonctions respiratoires, en particulier l'hyperréactivité (HR), et le remodelage des VA. La réactivité pulmonaire a été étudiée en différenciant les VAs centrales et périphériques.

MÉTHODES : Des rats mâles Brown Norway sensibilisés à l'Ovalbumine (Ova), recevaient une PA à l'Ova. Les PA étaient administrés 3 fois dans un modèle de PA multiple (MPM) ou une fois dans un modèle de PA unique (MPU). Deux jours (MPM) ou 24 h (MPU) après la dernière PA, les fonctions pulmonaires étaient évaluées et les lavages broncho-alvéolaires (LBA) étaient collectés. De plus, le tissu pulmonaire était fixé pour mesurer la masse de muscle lisse et le nombre de cellules caliciformes (CC).

RÉSULTATS : Dans le MPM, 48 h après la dernière PA, une augmentation significative de la résistance respiratoire totale, attribuable aux compartiments périphériques $(\mathrm{n}=8)$ a été observée. De plus, la masse de muscle lisse $(n=8)$, et le nombre de CC $(n=7-8)$ dans les VA centrales ont également été augmentés. Dans le MPU, la PA a entrainé une augmentation du nombre d'éosinophile dans les LBA $(n=7-10, p=0.02)$ et une augmentation de l'élastance.

DISCUSSION : Les PAs répétés chez le rat sensibilisé causent une HR attribuables aux compartiments pulmonaires périphériques. Cependant, le remodelage touche principalement les VA centrales suggérant des réponses différentes selon le compartiment pulmonaire. En conclusion, d'autres études sont nécessaires pour mieux comprendre les mécanismes par lesquels l'HR et le remodelage se développent et/ou persistent.

Remerciements : Dr Paul-André Risse

Soutenu par CIHR et le J.T. Fonds commémoratifs de recherches de Costello. SS ont été placés par un studentship de MUHC RI (2006-2007), étaient un destinataire d'une camaraderie doctorale d'asthme dans le lieu de travail (2007. 2008) et ont été choisis pour le programme de formation de santé respiratoire du Québec (2008-2009) 


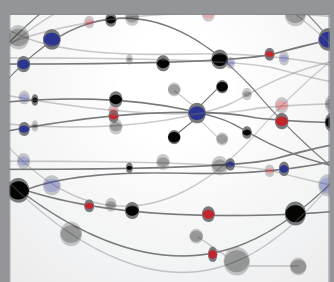

The Scientific World Journal
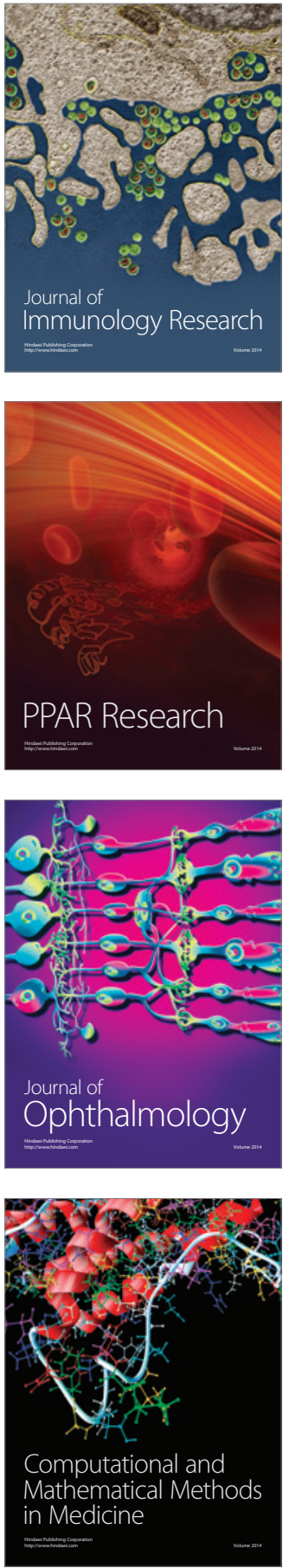

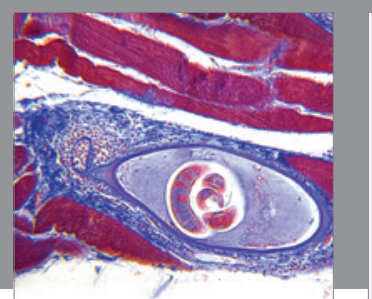

Gastroenterology Research and Practice

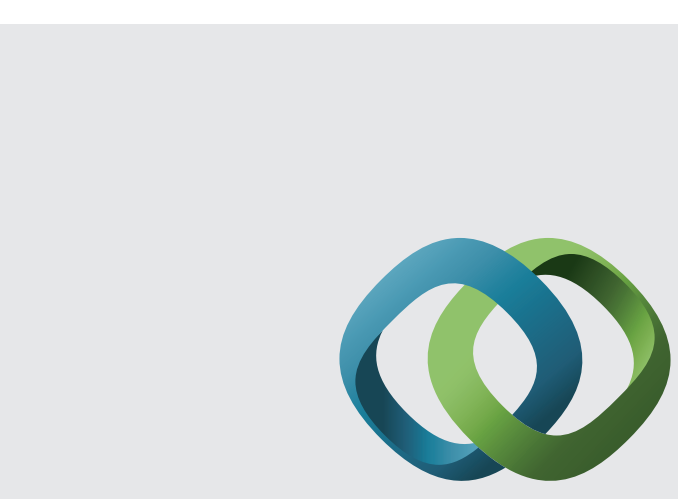

\section{Hindawi}

Submit your manuscripts at

http://www.hindawi.com
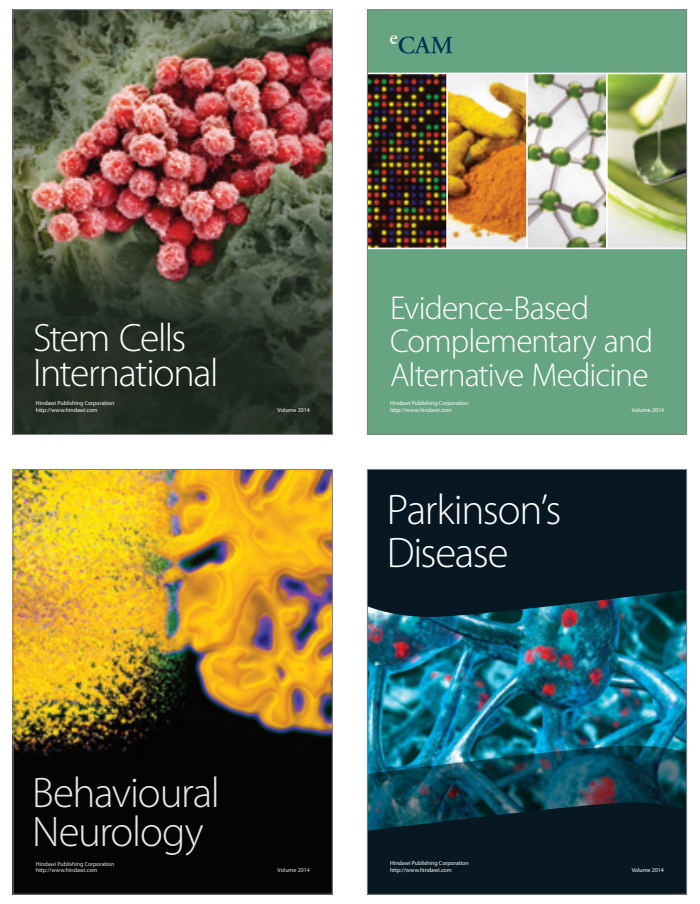
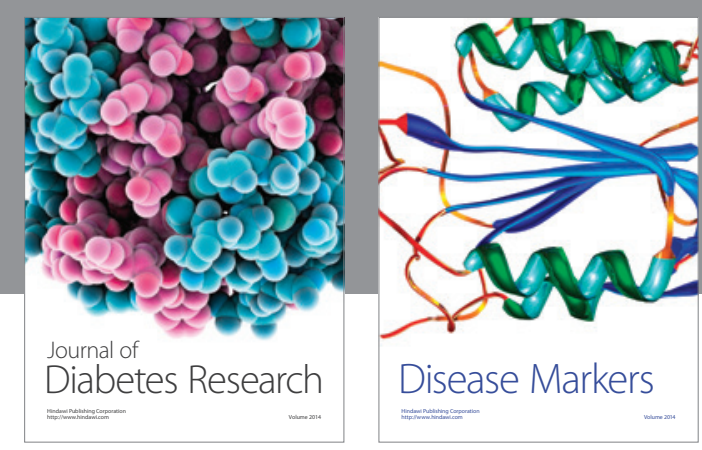

Disease Markers
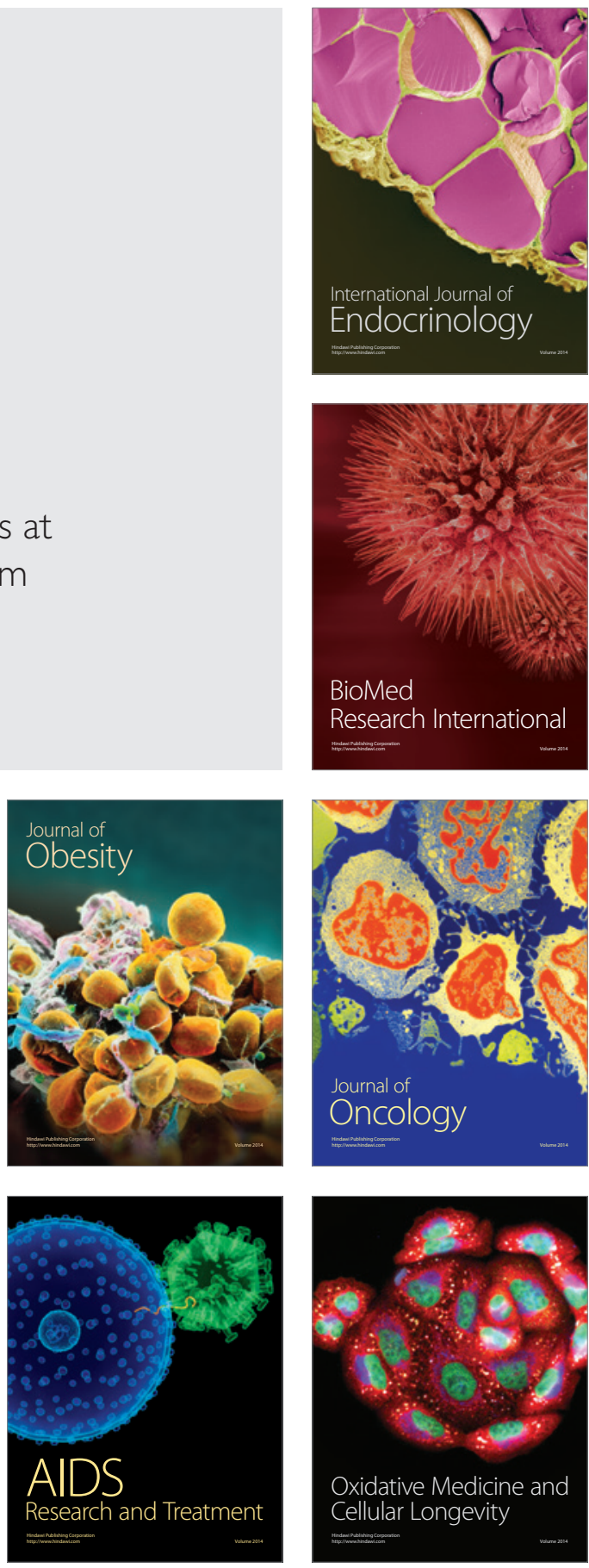